\title{
Price Dispersion in the Lab and on the Internet: Theory and Evidence
}

\author{
Michael R. Baye \\ John Morgan \\ Indiana University \\ Princeton University
}

August, 2001

\begin{abstract}
Price dispersion is ubiquitous in settings that closely approximate textbook Bertrand competition. We show (Propositions 1 and 2) that only a little bounded rationality among sellers is needed to rationalize such dispersion. A variety of statistical tests, based on data sets from two independent laboratory experiments and structural estimates of the parameters of our models, suggest that bounded rationality based theories of price dispersion organize the data remarkably well. Evidence is also presented which suggests that the models are consistent with data from a leading Internet price comparison site.

JEL Numbers: D43, C72

Keywords: Bertrand, Quantal Response Equilibrium, Epsilon Equilibrium.
\end{abstract}




\section{Introduction}

A puzzling empirical regularity has been identified in price setting environments where firms sell identical products: There is considerable price dispersion and transactions prices tend to be above marginal cost. For example, Figure 1 on page 32 shows that, with a few mouse clicks at the Internet price comparison site Shopper.com, a consumer can obtain a list of 10 firms offering prices for an Epson Expression 1600 Professional Edition scanner. These prices range from a low of $\$ 625.85$ all the way up to a high of $\$ 903.00$, and are inconsistent with Bertrand-Nash behavior: The range is 44.3 percent of the lowest price, and the coefficient of variation (defined as the ratio of the standard deviation of prices to the mean price) is 15.2 percent. ${ }^{1}$

While one might surmise that this casual evidence of price dispersion may be explained by transactions costs, imperfect information, differing seller costs, and so forth, similar patterns of price dispersion occur in laboratory settings where these considerations are absent by design. Plott (1982) surveys the results of numerous complete information homogeneous product pricing experiments, and notes that this institution generally results in "a higher variance in behavior" (p. 1513) than other market institutions, and that even after multiple rounds of experiments with the same subjects the "...adjustment [of price to marginal cost] tends to be from above and either converges [to marginal cost] slowly or does not converge at all." (p. 1498). He concludes that "...a slight upward bias relative to the competitive equilibrium, even when the number of firms is "large," appears to be part of the general properties of the posted-price institution" (p. 1514).

\footnotetext{
${ }^{1}$ There is also considerable evidence of price dispersion at traditional retail outlets; see Carlson and Pescatrice (1980), Pratt, Wise, and Zeckhauser (1979), Stigler (1961), Villas-Boas (1995), Warner and Barsky (1995), among others.
} 
This paper shows that introducing just a little bounded rationality among sellers goes a long way in reconciling theory with the price dispersion commonly observed on the Internet as well as in the lab. We begin in Section 2 by more formally documenting the pervasiveness of price dispersion in homogeneous product settings. Section 3 then develops equilibrium implications of bounded rationality models that are relevant for homogeneous product winner-take-all price competition. Our Propositions 1 and 2 show that, in these settings, models of bounded rationality based on solution concepts proposed by Radner (1980) and McKelvey and Palfrey (1995) generate price dispersion similar to that observed on the Internet and in the lab. Section 4 uses experimental data to structurally estimate the parameters of these pricing distributions. A variety of statistical tests offer considerable support for the bounded rationality hypothesis, and little support for the Nash hypothesis. We conclude in Section 5 by providing some evidence that data from the Internet is also consistent with bounded rationality models of price dispersion. All proofs are relegated to the Appendix.

\section{Price Dispersion in Homogeneous Product Mar- kets}

As Hal Varian (1980) noted over two decades ago, “...'the law of one price' is no law at all." Since theoretical explanations of the failure of the law of one price typically stress the role of search frictions (cf. Reinganum, 1979), information asymmetries (cf. Varian, 1980), or both (Burdett and Judd, 1983), one might expect that price dispersion would be trivial at price comparison sites on the Internet and non-existent in laboratory data where sellers compete in a classic Bertrand fashion. Unfortunately, 
this conclusion is not borne out in a number of empirical studies (cf. Brynjolfsson and Smith (2000), and Baye, Morgan, and Scholten (2001a); Plott (1982)). This section presents some additional evidence that price dispersion is ubiquitous in a variety of homogeneous product settings.

\subsection{Evidence from the Internet}

Price comparison sites have become an increasingly popular way to shop for merchandise on the web. One such site, Shopper.com, offers comparisons on over 100,000 consumer electronics products. Using a "spider" written in the PERL programming language, we downloaded data for the top 100 products on the Shopper.com site on March 26, 2001. This information includes the name of the product, the identity of all firms selling each product, each firm's reputational ranking, inventory, shipping costs, and list price. Based on the list prices, we constructed two statistics to summarize the level of price dispersion for the different products: the coefficient of variation (the sample standard deviation of prices charged for a product divided by the mean price of the product) and the range (the highest price minus the lowest price charged for a given product). ${ }^{2}$ Unlike the range, the coefficient of variation is a unitless measure of price dispersion that may be used to compare the relative dispersion of different products that sell for different prices.

Table 1 on pages 51-52 presents descriptive statistics for these data (in descending order of each product's coefficient of variation). The table illustrates that, even at a price comparison site like Shopper.com where consumers may costlessly observe an entire list of prices that different firms charge for identical electronics products, price

\footnotetext{
${ }^{2}$ These measures have been used in a variety of other studies, including Carlson and Pescatrice (1980), Sorensen (2000), and Baye, Morgan and Scholten (2001a,b).
} 
dispersion is ubiquitous. The average product in the sample sells for $\$ 456.44$, while the average range in prices is $\$ 119.43 .{ }^{3}$ The coefficients of variation range from a high of 28.5 percent (for a Sony VAIO personal computer) to zero (for Adobe Photoshop). The "law of one price" holds exactly for only three products, and these three products are sold by only a single firm. Expressed differently, for every product where two or more firms competed, the Internet data display coefficients of variation ranging from $1.9 \%$ up to $28.5 \%$ and price ranges from $\$ 5.17$ to $\$ 1607.00$.

\subsection{Evidence from the Lab}

Price dispersion is not only observed at Internet sites such as Shopper.com, but in controlled environments designed to exactly match textbook models of Bertrand competition. We now describe two sets of experiments that examine price setting in homogeneous product markets and show that price dispersion is also ubiquitous in controlled laboratory settings. Overviews of the experimental designs are provided below; the interested reader may refer to the cited papers for details.

Dufwenberg and Gneezy (1998) report on hand-run experiments in which twelve Dutch subjects participated in a ten round Bertrand pricing game. In each session, subjects competed in either a duopoly, triopoly, or quadopoly treatment with random rematching of subjects between rounds. Subjects selected integer prices between 2 and 100 (inclusive) in each round. The subject in a match choosing the lowest price

\footnotetext{
${ }^{3}$ Baye, Morgan, and Scholten (2001a) document that the levels of price dispersion reported in Table 1 are not an artifact of firms' listing "bogus prices" for the products or the date on which these data were collected. Indeed, they observe patterns of price dispersion similar to that in Table 1 both across time and for the top 1000 products at Shopper.com. Baye, Morgan, and Scholten (2001b) also provide evidence that the dispersion observed at Shopper.com is not an artifact of differences in shipping costs or vendor characteristics (such as inventories or reputation).
} 
was awarded a number of points (convertible into cash) equal to the price she selected. Thus, the monopoly price of 100 is also the highest price that subjects were permitted to select. The unique Nash equilibrium is for each subject to select a price equal to 2.

For the duopoly treatments in the Dufwenberg and Gneezy experiments (hereafter, DG), the average posted price was 33.33, with an interquartile range from 19 to 49 . Increasing the number of sellers from two to four decreased the average price to 25.75; however the interquartile spread remained fairly substantial, ranging from 5 to 33.5. The average lowest price also exceeded the Nash prediction. Under duopoly, the mean winning price was 27.52 , for the triopoly treatments it was 8.19 , and for the quadopoly treatments the average winning price was 8.51. While the mean (and median) prices observed declined from round 1 to round 10, the spread in prices actually increased from rounds 1 to round 10. The levels of price dispersion observed in these experiments are, in fact, much higher than what we observed in Table 1. For instance, in the duopoly experiments, the coefficient of variation for prices across all rounds was about $60 \%$. Price dispersion persisted even in the last round - the coefficient of variation here was about $52 \%$. The triopoly and quadopoly treatments yielded even greater dispersion across all rounds and in the last round. In short, recent homogeneous product price setting experiments with Dutch subjects resulted in prices above the Nash prediction and considerable price dispersion.

Similar conclusions may be drawn from experiments reported in Abrams, Sefton, and Yavas (1998), which were computer-run with U.S. subjects. In contrast to the DG experiments, Abrams, Sefton and Yavas (hereafter, ASY) used live buyers and live sellers. These experiments consisted of eight buyers and eight sellers participating 
in a 25 round pricing game. In each round a buyer received price quotes from two different sellers selected at random, and could either purchase from one of the sellers or refuse their offers and (possibly) exercise an outside option. ${ }^{4}$ The value of the object to a buyer was 120 points; hence, a buyer's surplus from accepting a price quote was simply the difference between 120 and the purchase price. A seller whose price quote was accepted by a buyer received points equal to the amount of the quote. The feasible set of price quotes that sellers could offer were integers from 0 to 200 inclusive. Thus, the monopoly price was 120 ; however, in contrast to the DG experiments, sellers were permitted to price above the monopoly price. Despite the more complicated experimental design, seller incentives are identical to those in the classical Bertrand setting: It is a Nash equilibrium for each seller to price at zero. ${ }^{5}$

As Figure 2 on page 33 shows, the ASY data are qualitatively similar to the DG experiments. This figure presents a measure of the spread in prices (the widest tick marks), the interquartile range (the rectangle), and the median price (the tick mark within the rectangle) for each of 25 rounds of the experiments. Notice that, while there is an initial decline in the median, spread, and interquartile range of prices, all three measures stabilize after 7 rounds to levels that exhibit not only considerable dispersion in prices, but where median prices are considerably in excess of Nash predictions. The coefficients of variation for the ASY data exceed those in Table 1 as

\footnotetext{
${ }^{4}$ In the ASY design, the outside option is such that, in any subgame perfect equilibrium, consumers would never choose to exercise it. For this reason, all tests reported below are based on pricing data from what they call the "Initial Bertrand Stage" of their experiment.

${ }^{5}$ This equilibrium is also subgame perfect. Due to the discreteness of the strategy space, there are two other subgame perfect equilibria: $p_{1}=p_{2}=1$ and $p_{1}=p_{2}=$ 2. The tests reported below are based on the conventional Nash hypothesis that $p_{1}=p_{2}=0$; however the conclusions are not affected by which of these three Nash equilibria is used for the null hypothesis.
} 
well as those reported above for the DG duopoly experiments.

\section{Theory}

While one may "explain away" price dispersion on the Internet by arguing that it stems from unobserved heterogeneities (cf. Gatti, 2000; Janssen and Moraga, 2000; Rosenthal, 1980; Spulber, 1995; Stahl, 2000; and Varian, 1980) or by the fact that it is costly for firms to post prices (Baye and Morgan, 2001), similar patterns are observed in laboratory settings that explicitly control for these and other frictions. Since significant dispersion is observed in two quite different environments, we offer a theoretical framework that helps explain the price dispersion observed in the field and in the lab.

\section{Preliminaries}

Consider an environment in which a set $N=\{1,2, \ldots n\}$ of $n \geq 2$ risk-neutral players compete to supply some homogeneous product. Let $\pi(p)$ denote the payoff to a monopolist charging a price $p$. Let $c$ be the initial breakeven price of a monopolist operating in this market. This price satisfies $\pi(c)=0$ and $\pi(p)<0$ for all $p<c$. Let $p^{M} \in \arg \max _{p \in \mathcal{P}} \pi(p)$ and $\pi^{M} \equiv \pi\left(p^{M}\right)>0$ denote the monopoly price and monopoly payoff, respectively. For simplicity, we assume that $\pi(p)$ is continuous and strictly increasing on the interval $\left[c, p^{M}\right]$, and restrict the players to choose prices from the set $\mathcal{P} \equiv\left[c, p^{M}\right]{ }^{6}$

Each player simultaneously chooses a price, $p_{i} \in \mathcal{P}$, and the player charging the

\footnotetext{
${ }^{6}$ One can readily extend all of the results below to cases where players are free to choose prices above the monopoly price.
} 
lowest price earns the monopoly payoff corresponding to that price. If several players tie for the lowest price, one of them is randomly selected to earn the monopoly payoff at the lowest price. Thus, if $\left(p_{1}, p_{2}, \ldots, p_{n}\right)$ are the prices chosen by the $n$ players, the (expected) payoff to player $i$ is given by:

$$
\pi_{i}\left(p_{1}, p_{2}, \ldots, p_{n}\right)=\left\{\begin{array}{lll}
\pi\left(p_{i}\right) & \text { if } & p_{i}<p_{j} \forall j \neq i \\
\frac{1}{m} \pi\left(p_{i}\right) & \text { if } & i \text { ties } m-1 \text { other players for low price } \\
0 & & \text { otherwise }
\end{array}\right.
$$

Let $\Phi$ be the set of all cumulative distribution functions on $\mathcal{P}$, so that a strategy for player $i$ is a probability measure $F_{i} \in \Phi$. Given a vector of strategies $F=$ $\left(F_{1}, F_{2}, \ldots, F_{n}\right)$, player $i$ 's expected payoff is $E \pi_{i}(F)=\int_{\mathcal{P}^{n}} \pi_{i}\left(p_{1}, p_{2}, \ldots, p_{n}\right) d F$. If we let $\Pi=\left(E \pi_{1}, E \pi_{2}, \ldots E \pi_{n}\right)$, then a homogeneous product pricing game is given by $\Gamma\left\langle N, \Phi^{n}, \Pi\right\rangle$.

Our analysis applies three solution concepts to homogeneous product pricing games: Nash equilibrium, $\varepsilon$-equilibrium, and quantal response equilibrium. The latter two solution concepts incorporate bounded rationality into an equilibrium framework.

Definition 0 A vector of strategies $F^{*}=\left(F_{1}^{*}, \ldots, F_{n}^{*}\right) \in \Phi^{n}$ comprises a Nash equilibrium of $\Gamma$ if, for all $i \in N$ and for all $F_{i}^{\prime} \in \Phi$,

$$
E \pi_{i}\left(F_{i}^{\prime}, F_{-i}^{*}\right)-E \pi_{i}\left(F_{i}^{*}, F_{-i}^{*}\right) \leq 0 .
$$

Definition 1 A vector of strategies $F^{\varepsilon} \in \Phi^{n}$ comprises an $\varepsilon$-equilibrium of $\Gamma$ if, for all $i \in N$, for all $F_{i}^{\prime} \in \Phi$, and a fixed $\varepsilon>0$ :

$$
E \pi_{i}\left(F_{i}^{\prime}, F_{-i}^{\varepsilon}\right)-E \pi_{i}\left(F_{i}^{\varepsilon}, F_{-i}^{\varepsilon}\right) \leq \varepsilon .
$$


Intuitively, an $\varepsilon$-equilibrium is a set of strategies with the property that no player can obtain more than $\varepsilon$ in additional payoffs by deviating from the prescribed strategies. This may arise because of bounded rationality, satisficing behavior, ${ }^{7}$ or because a Weber-Fechner-Stevens law holds with respect to just noticeable differences in individual perceptions of payoffs.

To define a quantal response equilibrium for homogeneous product pricing games, it is useful to let $E \pi_{i}\left(p_{i}, F_{-i}^{Q}\right)$ denote player $i$ 's expected payoff from charging a price $p_{i}$ when the other players adopt the vector of strategies $F_{-i}^{Q} \in \Phi^{n-1}$. Let $T_{i}$ map $E \pi_{i}\left(p_{i}, F_{-i}^{Q}\right)$ into the probability that player $i$ charges a price less than or equal to $p_{i}$.

Definition $2 A$ vector of strategies $F^{Q} \in \Phi^{n}$ comprises a quantal response equilibrium (QRE) if, for all $i \in N$ and $p_{i} \in \mathcal{P}$ :

$$
F_{i}^{Q}\left(p_{i}\right)=T_{i}\left(E \pi_{i}\left(p_{i}, F_{-i}^{Q}\right)\right)
$$

In a quantal response framework, nondegenerate distributions of player actions may arise either because of preference shocks (McFadden, 1984) or decision errors (Luce, 1959). In a QRE, the likelihood that players choose a particular strategy depends on the expected payoffs from that strategy. Strategies are determined by a decision rule (such as the logistic or power function) that is probabilistic and has the property that actions generating higher expected payoffs are more likely to be selected, although not necessarily with probability one. Each player's expected payoffs from different actions depend on the probability distributions of other players' actions. For a given probabilistic decision rule, a QRE requires that all players hold correct beliefs about the probability distributions of other players' actions. Anderson, Goeree, and Holt

\footnotetext{
${ }^{7}$ See March and Simon (1958).
} 
(1998) pioneered the techniques used below to solve for a quantal response equilibrium in games where the action space is continuous. ${ }^{8}$

\section{Analysis}

This subsection applies the above solution concepts to any homogeneous product pricing game, $\Gamma$. We begin with the familiar result that the unique symmetric Nash equilibrium in such a game entails breakeven pricing. The proof of this result is standard and hence is omitted.

Proposition 0 The following comprises a symmetric Nash equilibrium to $\Gamma$ : For all $p \in\left[c, p^{M}\right]$ and $i \in N, F_{i}^{*}(p)=1$.

Next, we examine $\varepsilon$-equilibria in homogeneous product pricing games. For the case of pure-strategies, $\varepsilon$-equilibrium behavior leads to prices and payoffs that do not substantially differ from Nash behavior. To be more precise, the following lemma shows that, in any pure-strategy $\varepsilon$-equilibrium to such a game, each player necessarily earns a payoff that is less than $\varepsilon$.

Lemma 1 In in any pure-strategy $\varepsilon$-equilibrium to $\Gamma$, players earn no more than $\varepsilon$.

Nonetheless, there does exist a symmetric (mixed-strategy) $\varepsilon$-equilibrium in which each player earns an expected payoff that exceeds $\varepsilon$, as the following proposition shows.

Proposition 1 For any $\varepsilon \in\left(0,\left(\frac{n}{n-1}\right)^{n-1} 2^{-n} \pi^{M}\right)$, the following comprises a symmetric $\varepsilon$-equilibrium to $\Gamma$ in which each player earns an expected payoff that exceeds

${ }^{8}$ Their theoretical analysis examines QRE in rent-seeking games. 
$\varepsilon:$ For all $p \in\left[c, p^{M}\right]$ and $i \in N$,

$$
F_{i}^{\varepsilon}(p)=\left\{\begin{array}{cl}
0 & \text { if } p<\pi^{-1}(\theta) \\
1-\left[\frac{\theta}{\pi(p)}\right]^{\frac{1}{n-1}} & \text { if } p \in\left[\pi^{-1}(\theta), p^{M}\right) \\
1 & \text { if } p=p^{M}
\end{array}\right.
$$

where

$$
\theta=\left[\varepsilon^{n-1}\left(\frac{n}{n-1}\right)^{n-1} \pi^{M}\right]^{\frac{1}{n}}
$$

Several aspects of this equilibrium are worth noting. First, it follows from Lemma 1 that the $\varepsilon$-equilibrium in Proposition 1 Pareto dominates all pure strategy $\varepsilon$ equilibria, as each player earns an expected payoff in excess of $\varepsilon$. Second, as the number of competing players increases, prices become more concentrated in the tails of the distribution. Third, there is a jump in the distribution of prices at the monopoly price, and the size of this jump at $p^{M}$ is increasing in the number of players. In contrast, there is no point mass at the lower support of the distribution of prices, and the lower support is decreasing in $n$. Finally, one can show that, for small $\varepsilon$, each player's expected payoff is increasing in $\varepsilon$ and decreasing in $n$; thus greater competition or lower levels of bounded rationality lead to more competitive outcomes. In the sequel, we test several of these implications using both field and laboratory data.

Our second main proposition identifies a symmetric quantal response equilibrium in homogeneous product pricing games. Following Lopez-Acevedo (1997), suppose that the probability (more formally the density) with which player $i$ chooses price $p$ is generated by the power function decision rule with (bounded rationality) parameter 
$\lambda \in\left[0, \frac{1}{n-1}\right) .{ }^{9}$ In this case,

$$
T_{i}\left(E \pi_{i}\left(p, F_{-i}\right)\right)=\int_{c}^{p} \frac{E \pi_{i}\left(q, F_{-i}\right)^{\lambda}}{\int_{c}^{p^{M}} E \pi_{i}\left(t, F_{-i}\right)^{\lambda} d t} d q .
$$

Proposition 2 For any $\lambda \in\left[0, \frac{1}{n-1}\right)$, let $T_{i}$ be defined by equation (3). Then the following comprises a symmetric QRE to $\Gamma$ : For all $p \in\left[c, p^{M}\right]$ and $i \in N$,

$$
F_{i}^{Q}(p)=1-\left(\frac{g\left(p^{M}\right)-g(p)}{g\left(p^{M}\right)-g(c)}\right)^{\frac{1}{1+\lambda-n \lambda}}
$$

where $g(p) \equiv \int \pi(p)^{\lambda} d p+K$.

It is useful to contrast the distribution of prices arising in Proposition 1 with that in Proposition 2. First, in contrast to the $\varepsilon$-equilibrium, there is no jump in the distribution of prices at $p^{M}$ under the QRE. Second, again in contrast to the $\varepsilon$ equilibrium, the lower support of the distribution of prices in the QRE is independent of the bounded rationality parameter $(\lambda)$. Finally, the limit of both the $\varepsilon$-equilibrium and QRE correspond to the symmetric Nash equilibrium. To see this, note that as $\varepsilon$ tends to zero, $\theta$ goes to zero and the equilibrium in Proposition 1 converges to that in Proposition 0. Similarly, as $\lambda \rightarrow \frac{1}{n-1}$, increasingly more of the probability mass in the QRE is allocated to prices close to $c$ and the equilibrium in Proposition 2 also converges to that in Proposition 0 . At the other extreme, as $\lambda \rightarrow 0$, the decision error component of the QRE strategies overwhelms the weight attached to relative expected profits and one obtains random behavior (prices chosen uniformly on $\left.\left[c, p^{M}\right]\right)$ as a symmetric QRE. Clearly, if $\varepsilon \geq \pi^{M}$, random behavior is also a

\footnotetext{
${ }^{9}$ We examine behavior for the power function rather than the logistic specification. This choice is motivated purely by analytical tractability; we were able to obtain closed-form representations for equilibrium pricing strategies only under the power function specification (see Proposition 2 below).
} 
symmetric $\varepsilon$-equilibrium. Thus, both extreme assumptions of rationality are nested within the $\varepsilon$-equilibrium and QRE frameworks.

\section{Data Analysis}

In our view, a theory of behavior in homogeneous product pricing games should be broadly applicable in environments that approximate winner-take-all competition. As we noted above, price comparison sites on the Internet as well as the ASY and DG experiments share these characteristics. Since the ASY and DG data stem from controlled experiments that, by design, match the conditions of the model given in Section 3, we use these data to formally analyze the theoretical models presented above. Throughout, we organize the experimental data as follows: For each treatment (duopoly, triopoly, quadopoly) in the DG experiments, we pool both sessions and report separate results for data based on all rounds and the last round (as this most closely corresponds to the one-shot game). Similarly, we pool all duopoly sessions of the ASY experiments and analyze data pooled over all rounds as well data from only the last round.

We first compare the empirical cumulative distribution of prices to that predicted under the two polar rationality assumptions: Nash behavior and random behavior (where all prices between the competitive and monopoly price are equally likely). The results for all rounds are shown in Figures 3-6 on pages 34-37. In all of these figures, the empirical distributions of prices lie mostly between the two extreme behavioral hypotheses. Moreover, despite considerable differences in experimental designs, the DG and ASY duopoly experiments yield qualitatively similar empirical distributions of prices. The observed data do not appear consistent with the Nash hypothesis, 
nor are the data consistent with random behavior. As one moves from two-player to four-player treatments, lower prices become more frequently observed than higher prices. Nonetheless, the empirical distribution of prices does not appear to converge to the Nash prediction. Finally, notice in Figures 3 and 6 that, at the monopoly price, there is a distinct upward jump in the empirical distribution of prices. A similar, but less pronounced effect is present in Figure 5. On balance, the experimental data look similar to the field data displayed in Figure 1.

One might speculate that the observed departure from Nash behavior stems from inexperienced subjects or repeated play strategies that sustain cooperative outcomes in early rounds. However, as Figures $7-10$ on pages $38-41$ show, data from the last round exhibits features similar to those shown in Figures 3-6. One major difference in the last round data is that the upward jumps at the monopoly price are more pronounced, particularly in Figures 7 and 10.

To summarize, observed behavior in two independent sets of experiments with subjects from different countries and considerably different experimental procedures suggest that behavior in pricing games is qualitatively consistent across experimental conditions and lies between the Nash prediction and random behavior. The observed distributions of prices in these experiments share features observed in field data. In light of this, we use this experimental data to estimate the bounded rationality parameters associated with the $\varepsilon$-equilibrium and QRE strategies defined in Propositions 1 and 2.

\section{Hypotheses}

In the ASY and DG experimental designs, the monopoly profit function is $\pi(p)=p$ 
for all $p \in \mathcal{P}$. Applying the results from Propositions 0-2 to the strategy space in the ASY experiments leads to the following predictions about the distributions of prices under the three competing equilibrium concepts:

$$
\begin{gathered}
\text { Nash Hypothesis: } F_{i}^{*}(p)=1 \text { if } 0 \leq p \leq 120 \\
\varepsilon \text {-equilibrium Hypothesis : } F_{i}^{\varepsilon}(p)= \begin{cases}0 & \text { if } p<\theta \\
1-\left(\frac{\theta}{p}\right)^{\frac{1}{n-1}} & \text { if } \theta \leq p<120 \\
1 & \text { if } p=120\end{cases} \\
\text { QRE Hypothesis : } F_{i}^{Q}(p)=1-\left(1-\left(\frac{p}{120}\right)^{1+\lambda}\right)^{\frac{1}{1+\lambda-n \lambda}} \text { if } 0 \leq p \leq 120 .
\end{gathered}
$$

We also consider the naive hypothesis that subjects choose strategies at random:

$$
\text { Random Behavior Hypothesis: } F_{i}^{R}(p)=\frac{p}{120} \quad \text { if } \quad 0 \leq p \leq 120
$$

Similar hypotheses obtain for the DG data, except that the monopoly price is 100 and the minimum feasible price is 2 .

\section{Estimation}

The expressions for the $\varepsilon$-equilibrium and QRE solution concepts in equations (5) and (6) depend on the number of players $(n)$, the monopoly price, and the (unobservable) bounded rationality parameters $\theta$ and $\lambda$. Our approach is to use the experimental data to estimate $\theta$ and $\lambda$. The hypothesis tests described in the next section are based on parameter estimates for each data set. These parameter estimates were obtained in the following manner. 
For each price $p$ in the strategy space of an experiment, let $\widehat{F}(p)$ denote the empirical cumulative distribution function associated with that price; that is, $\widehat{F}(p)$ is the fraction of prices observed in a given data set that is less than or equal to $p$. Similarly, let $F^{\varepsilon}(p ; \theta)$ and $F^{Q}(p ; \lambda)$ denote the predicted distributions of prices under the $\varepsilon$-equilibrium and the QRE as a function of their respective bounded rationality parameters. For the ASY data, these expressions are given by equations (5) and (6). For each data set, we estimate the parameters $\theta$ and $\lambda$ by minimizing the sum of squared errors between the empirical cumulative distribution function and the theoretical cumulative distribution function. ${ }^{10}$ These parameter estimates are reported in Table 2 on page 53.

Several aspects of these estimates are worth noting. Recall that in the QRE, feasible values of $\lambda$ are bounded from above by $\frac{1}{n-1}$, which declines as the number of players increases. The closer the parameter estimate is to $\frac{1}{n-1}$, the closer is the QRE prediction to the Nash prediction. The estimates of $\lambda$ reported in Table 2 for both the U.S. and Dutch duopoly experiments are considerably less than 1, thus suggesting a departure from Nash behavior. Specifically, the estimates of $\lambda$ based on all rounds of U.S. duopoly data are 76.1 percent of that under Nash behavior. Similarly, for the Dutch duopoly all round data, the estimated value of $\lambda$ is 78.4

${ }^{10} \mathrm{To}$ account for the discrete strategy space, we adapt equation (6) for the ASY data sets as follows: Let $\underline{p}$ denote the largest integer strictly less than lowest price in the strategy space. We estimated using

$$
F_{i}^{Q}(p)=1-\left(1-\left(\frac{p-\underline{p}}{p^{M}-\underline{p}}\right)^{1+\lambda}\right)^{\frac{1}{1-\lambda+n \lambda}} .
$$

This ensures that both random behavior and Nash remain special cases of QRE with $\lambda=0$ and $\lambda=\frac{1}{n-1}$, respectively. A similar adaptation is employed for the DG data sets. 
percent of that under Nash behavior. Moreover, there is no obvious convergence of the QRE to Nash behavior as the number of players increases from 2 to 4: In the triopoly treatment the estimated value of $\lambda$ is 93.6 percent of that under Nash, and for the quadopoly treatment the estimated value is 86.1 percent of that under Nash behavior. Examining the estimates of last round data, the evidence for convergence to Nash is mixed. In the U.S. duopoly treatment, the estimate of $\lambda$ increases to 90.7 percent of Nash, whereas the estimate for the Dutch duopoly treatment decreases to only 45.7 percent of that under Nash behavior. In contrast, estimates of $\lambda$ for the last round triopoly and quadopoly treatments are both in excess of 98 percent of those under Nash behavior.

We now turn to parameter estimates for the $\varepsilon$-equilibrium reported in Table 2 . Recall that in an $\varepsilon$-equilibrium, feasible values of $\theta$ are bounded from below by 0 , which corresponds to Nash behavior. Unlike the case of the QRE, this lower bound is independent of the number of players. The estimates of $\theta$ based on all rounds of data for the duopoly experiments are considerably above zero, and generally decline as we move from duopoly to triopoly to quadopoly. This is consistent with the theory: Equation (2) implies that for a given $\varepsilon, \theta$ is decreasing in $n$.

Given estimates of $\theta$, we may invert equation (2) to obtain estimates of $\varepsilon$. These estimates of $\varepsilon$ are reported in Table 3 on page 53. As is readily seen, the degree of bounded rationality is quite small. The largest estimate of $\varepsilon$ is $\$ 0.06$, which means that a subject will not deviate from a given strategy unless doing so increases her payoff by more than six US cents. The median estimate of $\varepsilon$ is less than one cent. We will see below that even these small values of $\varepsilon$ are consistent with behavior that differs significantly from the Nash prediction. 
Figures 11-14 on pages 42-45 show the estimated distributions of prices for the $\varepsilon$-equilibrium and QRE, along with the empirical distribution based on all rounds for each treatment. These figures suggest that our estimates of $\lambda$ and $\theta$ predict theoretical distributions that are fairly close to the observed distributions. However, the estimated distributions for QRE tend to underpredict the frequency of prices near the monopoly price. In Figures 11 and 14, for instance, the empirical distribution of prices jumps up at the monopoly price, and this jump is not consistent with a QRE. In contrast, the estimated $\varepsilon$-equilibrium price distributions correctly predict a jump at the monopoly price, but the size of this jump is larger than that observed in the data.

Figures 15-18 on pages 46-49 display results based on the last round data for each treatment. These figures are qualitatively similar to those in Figures 11-14, which are based on all rounds of data. However, the upward jumps in the empirical distribution of prices near the monopoly price tend to be more pronounced in the last round data. Figure 18 shows that the estimated $\varepsilon$-equilibrium for the quadopoly treatment predicts the observed jump in the empirical distribution of prices, even though the implied value of $\varepsilon$ for that case is close to zero.

It is interesting to note that the distributions of prices under the estimated QRE and $\varepsilon$-equilibrium roughly bracket the empirical distribution of prices for each treatment. The $\varepsilon$-equilibrium estimates tend to form an upper bound on the empirical distribution for low prices, and a lower bound on for higher prices. The QRE estimates, on the other hand, tend to form a lower bound on the empirical distribution for lower prices and an upper bound for higher prices. This suggests that a combination of the two concepts might provide even greater explanatory power. The theoretical 
foundations of what might be termed an $\varepsilon$-QRE are beyond the scope of the present paper.

\section{Goodness of Fit}

Table 4 on page 54 provides alternative measures of how well the estimated distributions of prices under the $\varepsilon$-equilibrium and QRE solution concepts fit the data. To provide a benchmark for interpreting these numbers, we also present these goodness of fit measures for the Nash hypothesis and random behavior hypothesis. Based on the sum of squared errors metric, QRE and $\varepsilon$-equilibrium lead to a substantial improvement over Nash and random behavior. The bounded rationality models also outperform the Nash and random behavior models in the sup norm metric (which measures the maximum distance between the observed and estimated distributions of prices). ${ }^{11}$ Indeed, regardless of the metric selected, the estimated QRE and $\varepsilon$ equilibrium price distributions fit the data better than the Nash hypothesis and random behavior hypothesis.

To summarize, despite the fact that only small departures from full rationality are implied by the estimates in Table 2 , the models of bounded rationality are superior to the Nash (or random behavior) predictions at organizing the data. Next, we employ a variety of hypothesis tests to formally test the data against the hypotheses of QRE, $\varepsilon$-equilibrium, Nash, and random behavior.

\footnotetext{
${ }^{11}$ Formally, the sup norm metric is

$$
\max _{p \in\left[c, p^{M}\right]}|F(p)-\hat{F}(p)|
$$
}

where $F(\cdot)$ is the (estimated) theoretical distribution of prices for a given solution concept and $\hat{F}(\cdot)$ is the empirical distribution of prices. 


\section{Tests}

We report the results of four different types of hypothesis tests applied to each of the data sets. Table 5 on page 55 summarizes standard t-tests of the hypothesis that the mean of the empirical distribution of prices is equal to the mean of the theoretical distribution of prices under four null hypotheses ( $\varepsilon$-equilibrium, QRE, random behavior, and Nash). Table 6 presents results of sign-tests for equality of medians between the empirical distribution of prices and that under each the null hypotheses. Table 7 reports the results of chi-squared tests for equality of the empirical and estimated theoretical distributions under each null hypothesis, while Table 8 reports the results of tests for equality of standard deviations between the empirical and theoretical distributions of prices under each null hypothesis.

Overall, the statistical evidence favors the bounded rationality models of pricing behavior over Nash and random behavior. For the duopoly treatments, we fail to reject the null hypothesis of $\varepsilon$-equilibrium behavior in 11 of 16 hypothesis tests. Under QRE, we fail to reject in 9 of 16 tests. In contrast, Nash behavior is rejected in all of the tests and random behavior is rejected in three-fourths of the tests. In all cases where we fail to reject the QRE hypothesis, we also fail to reject the $\varepsilon$ equilibrium hypothesis; however, in some cases where the QRE solution concept is rejected, we fail to reject the $\varepsilon$-equilibrium solution concept.

The statistical support for the bounded rationality models is more mixed in the triopoly and quadopoly data. For these treatments, we fail to reject $\varepsilon$-equilibrium in only 5 of 16 tests. Likewise, we fail to reject QRE behavior in 5 of 16 tests. Still, both of these hypotheses fare better than random behavior (which we fail to reject in only 2 of 16 cases) and the Nash hypothesis (which is rejected in all cases). 
Looking in more detail at the test of equality of means in Table 5, we fail to reject the $\varepsilon$-equilibrium hypothesis in all cases but one (Dutch triopoly, all rounds). Thus, the $\varepsilon$-equilibrium hypothesis appears to be quite useful in predicting the mean price, regardless of the experience of subjects or the competitiveness of the pricing environment. For the duopoly treatments, QRE does almost as well in that it is only rejected for the US all rounds data. For the triopoly and quadopoly treatments, we fail to reject QRE using last round data but reject it when we pool all rounds. The mean prices predicted under Nash and random behavior are overwhelmingly rejected in the data; in all cases, the Nash predicts prices that are too low and random behavior predicts prices that are too high.

Table 6 on page 56 shows that QRE is more successful than the other three hypotheses at predicting median prices. In particular, QRE is rejected only twiceonce under duopoly (US, all rounds) and once under quadopoly (all rounds). In contrast, the $\varepsilon$-equilibrium is rejected in all triopoly and quadopoly treatments. Once again, the predictions of Nash and random behavior are overwhelmingly rejected in the data. Random behavior consistently predicts a median price that is too high, while the Nash prediction is too low.

In Table 7 on page 57 , we report the results of chi-squared tests for the equality 
of the observed and theoretical distributions under each of the null hypotheses. ${ }^{12} \mathrm{We}$ reject the hypothesized $\varepsilon$-equilibrium pricing distribution only once under duopoly, while the hypothesized pricing distribution under QRE is rejected twice (both US and Dutch, all rounds). Neither hypothesis does particularly well for triopoly and quadopoly: the $\varepsilon$-equilibrium solution concept is rejected in all cases and QRE in all cases but one (quadopoly, last round). Nonetheless, the QRE and $\varepsilon$-equilibrium solution concepts still do better than random behavior and Nash, which are rejected in every case.

Finally, Table 8 on page 58 reports tests of the equality of the observed and theoretical standard deviations in prices under each hypothesis. These tests reveal that, for data pooled across all rounds, random behavior does a better job at predicting the standard deviation in prices than the other three hypotheses: The price dispersion observed in the data exceeds that predicted under the Nash and bounded rationality hypotheses. However, in the last round data (where subjects are experienced and the underlying game most closely resembles the one-shot game on which the theory is based), the $\varepsilon$-equilibrium does a good job of predicting price dispersion. Specifically, we cannot reject the hypothesis that the observed and predicted $\varepsilon$-equilibrium standard deviations are equal in the Dutch duopoly, triopoly, and quadopoly treatments.

\footnotetext{
${ }^{12}$ For each estimated theoretical distribution, we constructed bins such that, under the associated theoretical distribution, an equal number of price realizations are expected in each bin. We then constructed the statistic

$$
s=\sum_{i=1}^{3}\left(\frac{N_{i}-E N_{i}}{E N_{i}}\right)^{2}
$$

where $N_{i}$ denotes the actual number of price realizations observed in bin $i$ and $E N_{i}$ denotes the expected number of price observations in bin $i$ under the relevant null hypothesis. Three bins were used to insure that for all $i, E N_{i} \geq 5$.
} 


\section{Discussion}

The theoretical results presented in Section 3, coupled with the empirical evidence in Section 4, suggests that a little bounded rationality goes a long way towards rationalizing the price dispersion observed in homogeneous product settings. Based on two different experimental datasets with significant differences in treatments (duopoly, triopoly, and quadopoly), differences in the nationality of subjects (American vs. Dutch), and differences in experimental designs (live versus robot buyers, outside options vs. no outside options, hand-run vs. computerized environments), we find considerable statistical support for the hypotheses that subjects are pricing in a manner consistent with models of bounded rationality.

In light of these findings, one might wonder whether these models are also a plausible explanation for the price dispersion observed on the Internet and documented in Table 1. While the absence of data on firms' costs and other variables precludes us from providing structural estimates and tests with these data, we conclude by providing some evidence that models of bounded rationality are also consistent with Internet data.

Proposition 1 predicts that a disproportionate number of firms will post the highest (monopoly) price for a given product. For the Shopper.com data summarized

in Table 1, two or more firms were tied for listing the highest price in $13.5 \%$ of the products for which there were multiple price listings. In contrast, for only $8.4 \%$ of products were two or more firms were tied for the lowest price. This mass observed in the data at the highest price for each product is consistent with the theory, which predicts a discrete jump in the cumulative distribution function at the monopoly price. 
Models of bounded rationality also shed light on an empirical regularity documented in Baye, Morgan, and Scholten (2001a). Based on a data set consisting of 4 million observations at Shopper.com for the top 1000 electronic products sold between August 2, 2000 and March 1, 2001, they find that the coefficient of variation in prices tend to increase as the number of firms listing prices rises from 2 to 5 , and then decreases as the number of firms increases from 5 to 30 . While this finding is based on regression analysis, the general pattern can easily be seen graphically in Figure 19 on page 50. A qualitatively similar pattern holds for the $\varepsilon$-equilibrium for small amounts of bounded rationality. In Figure 20 on page 50, we plot the theoretical coefficient of variation as a function of the number of sellers where $\varepsilon=1$ cent based on the demand and cost parameters in the DG experiments. As the figure illustrates, even for very small levels of bounded rationality (one cent), the coefficient of variation increases up to 4 sellers and then decreases thereafter. Even as the number of sellers grows large, there is significant price dispersion predicted by the model. In short, while the levels of price dispersion observed in lab are predicted (and observed) to be higher than those observed on the Internet, only a small degree of bounded rationality is needed to generate significant dispersion displaying the "up and down" pattern shown in Figures 19 and 20. 


\section{A Appendix}

\section{Proof of Lemma 1}

Without loss of generality, consider an $\varepsilon$-equilibrium in which players $1,2, \ldots, k$ charge a price of $p^{\varepsilon}$ and the remaining $n-k$ players charge a strictly greater price. Players $i \leq k$ thus earn a payoff of $E \pi_{i}=\pi\left(p^{\varepsilon}\right) / k$, while players $j>k$ earn payoffs of zero.

Case 1: $k>1$.

If player $i \leq k$ charges $p^{\varepsilon}$ she earns $\pi\left(p^{\varepsilon}\right) / k$, and if she deviates by charging a slightly lower price she earns no more than $\pi\left(p^{\varepsilon}\right)$. By hypothesis, the initial constellation of prices comprises an $\varepsilon$-equilibrium, so it follows that

$$
\pi\left(p^{\varepsilon}\right) \leq \varepsilon\left(\frac{k}{k-1}\right)
$$

Hence, each player $i \leq k$ earns a payoff of $E \pi_{i} \leq \varepsilon$ and each player $j>k$ earns a payoff of $E \pi_{j}=0$.

Case 2: $k=1$.

If player $j>k$ conforms she earns a payoff of 0 . If she deviates by undercutting $p^{\varepsilon}$ she earns no more than $\pi\left(p^{\varepsilon}\right)$. By hypothesis, the initial constellation of prices comprises an $\varepsilon$-equilibrium, so it follows that

$$
\pi\left(p^{\varepsilon}\right) \leq \varepsilon
$$

This implies that no player earns more than $\varepsilon$.

\section{Proof of Proposition 1}

Since $\pi(\cdot)$ is continuous and strictly increasing on $\left[c, p^{M}\right], \pi^{-1}(\cdot)$ exists. For a given 
$\varepsilon \in\left(0,\left(\frac{n}{n-1}\right)^{n-1} 2^{-n} \pi^{M}\right)$, we will show that the strategies in equation (1) comprise a symmetric $\varepsilon$-equilibrium, and furthermore, that $E \pi_{i}\left(F^{\varepsilon}\right)>\varepsilon$ for all $i \in N$.

First, observe that by charging $p \in\left[\pi^{-1}(\theta), p^{M}\right)$ when the other $n-1$ players adopt strategies $F_{-i}^{\varepsilon}$, player $i$ 's expected payoff is

$$
\begin{array}{r}
E \pi_{i}\left(p, F_{-i}^{\varepsilon}\right)=\pi(p)\left(1-F_{i}^{\varepsilon}(p)\right)^{n-1} \\
=\pi(p)\left[\frac{\theta}{\pi(p)}\right] \\
=\theta .
\end{array}
$$

Hence, player $i$ 's expected payoff is constant on this interval. If player $i$ prices below $\pi^{-1}(\theta)$, she earns $\pi(p)<\theta$. When player $i$ prices at $p^{M}$, she earns $\pi\left(p^{M}\right)$ only if all other $n-1$ players also charge $p^{M}$. Thus,

$$
\begin{array}{r}
E \pi_{i}\left(p^{M}, F_{-i}^{\varepsilon}\right)=\left[\operatorname{Pr}\left(p_{i}=p^{M}\right)\right]^{n-1} \frac{\pi^{M}}{n} \\
=\left[\frac{\theta}{\pi^{M}}\right] \frac{\pi^{M}}{n} \\
=\frac{\theta}{n} .
\end{array}
$$

Thus, if player $i$ plays according to $F_{i}^{\varepsilon}$ when the other $n-1$ players also use $F_{i}^{\varepsilon}$, her expected payoff is:

$$
\begin{array}{r}
E \pi_{i}\left(F^{\varepsilon}\right)=\operatorname{Pr}\left(p_{i}<p^{M}\right) \theta+\operatorname{Pr}\left(p_{i}=p^{M}\right) \frac{\theta}{n} \\
=\theta\left[1-\left(\frac{\theta}{\pi^{M}}\right)^{\frac{1}{n-1}}\left(\frac{n-1}{n}\right)\right] .
\end{array}
$$

The best deviation available to player $i$ is to charge a price $p \in\left[\pi^{-1}(\theta), p^{M}\right)$. In this case, she earns expected payoffs of $\theta$. The expected gain from such a deviation, however, is only

$$
\left[\frac{\theta}{\pi^{M}}\right]^{\frac{1}{n-1}} \theta\left(\frac{n-1}{n}\right) \leq \varepsilon
$$


which implies that $F^{\varepsilon}$ constitutes a symmetric $\varepsilon$-equilibrium.

Since $\varepsilon<\left(\frac{n}{n-1}\right)^{n-1} 2^{-n} \pi^{M}$, it is a routine matter to verify that

$$
E \pi_{i}\left(F^{\varepsilon}\right)=\theta\left[1-\left(\frac{\theta}{\pi^{M}}\right)^{\frac{1}{n-1}}\left(\frac{n-1}{n}\right)\right]>\varepsilon .
$$

\section{Proof of Proposition 2}

Recall that a symmetric QRE satisfies

$$
F_{i}^{Q}(p)=T_{i}\left(E \pi_{i}\left(p, F_{-i}^{Q}\right)\right)
$$

for all $i \in N$. Using the definition of $T_{i}$, differentiating, and imposing symmetry yields:

$$
f_{i}^{Q}(p)=\frac{\left[1-F_{i}^{Q}(p)\right]^{(n-1) \lambda} \pi(p)^{\lambda}}{\mu}
$$

where $\mu \equiv \int_{-\infty}^{\infty}\left(\pi(t)\left(1-F_{i}^{Q}(t)\right)^{n-1}\right)^{\lambda} d t$.

We may rewrite this expression as

$$
\int\left[1-F_{i}^{Q}(p)\right]^{-(n-1) \lambda} d F_{i}^{Q}=\int \frac{1}{\mu} \pi(p)^{\lambda} d p .
$$

Integrating yields

$$
-\frac{1}{1+\lambda-n \lambda}\left(1-F_{i}^{Q}(p)\right)^{1+\lambda-n \lambda}=\frac{1}{\mu}(g(p)-K)
$$

where $-K$ is a constant of integration. Solving for $F_{i}^{Q}$ we obtain

$$
F_{i}^{Q}(p)=1-\left(-\frac{1+\lambda-n \lambda}{\mu}(g(p)-K)\right)^{\frac{1}{1+\lambda-n \lambda}} .
$$

Using the fact that $F_{i}^{Q}\left(p^{M}\right)=1$ yields

$$
F_{i}^{Q}(p)=1-\left(\frac{1+\lambda-n \lambda}{\mu}\left(g\left(p^{M}\right)-g(p)\right)\right)^{\frac{1}{1+\lambda-n \lambda}}
$$


Finally, using the fact that $F_{i}^{Q}(c)=0$ gives us

$$
\mu=(1+\lambda-n \lambda)\left(g\left(p^{M}\right)-g(c)\right)
$$

Substituting $\mu$ into equation (7) yields equation (4). Finally, it is straightforward to verify that $F_{i}^{Q}$ is a well-defined cdf. 


\section{References}

[1] Abrams, E., M. Sefton, and A. Yavas, "An Experimental Comparison of Two Search Models," mimeo, The Pennsylvania State University, July, 1998.

[2] Anderson, S., J. Goeree, and C. A. Holt, "Rent-seeking with Bounded Rationality: An Analysis of the All-Pay Auction," Journal of Political Economy, 106 (1998), pp. 828-853.

[3] Baye, M. and J. Morgan, "Information Gatekeepers on the Internet and the Competitiveness of Homogeneous Product Markets, American Economic Review, 91 (2001), pp. 454-74.

[4] Baye, Michael R., John Morgan, and Patrick Scholten, "Price Dispersion in the Small and in the Large: Evidence from an Internet Price Comparison Site," mimeo, 2001a.

[5] Baye, Michael R., John Morgan, and Patrick Scholten, "Pricing and Reputation on the Internet," mimeo, 2001b.

[6] Brynjolfsson, Erik and Michael D. Smith, "Frictionless Commerce? A Comparison of Internet and Conventional Retailers," MIT Sloan School of Managment Working Paper, July 2000.

[7] Carlson, J. and Pescatrice, "Persistent Price Distributions," Journal of Economics and Business, Fall 1980.

[8] Dufwenberg, M. and U. Gneezy, "Price Competition and Market Concentration: An Experimental Study," CentER Discussion Paper No. 9827, March, 1998. 
[9] Gatti, J. Rupert J., "Equilibrium Price Dispersion with Sequential Search," mimeo, Cambridge University, November 2000.

[10] Janssen, Maarten and Jose Luis Moraga, "Pricing, Consumer Search and the Size of Internet Markets," mimeo, Tinbergen Institute Rotterdam, June 2000.

[11] Lopez-Acevedo, G., "Quantal Response Equilibria for Posted Offer Markets," Estudios Económicos, 12 (1997), pp. 95-131.

[12] Luce, R., Individual Choice Behavior: A Theoretical Analysis. New York: Wiley \& Sons, 1959.

[13] March, J. G. and H. A. Simon, Organizations, New York, 1958.

[14] McFadden, D., "Econometric Analysis of Qualitative Response Models," in Handbook of Econometrics (Z. Griliches and M. Intriligator, eds.). Amsterdam: Elsevier, 1984.

[15] McKelvey, R. and T. Palfrey, "Quantal Response Equilibria for Normal Form Games," Games and Economic Behavior, 10 (1995), pp. 6-38.

[16] Plott, C., "Industrial Organization Theory and Experimental Economics," Journal of Economic Literature 20 (1982), pp. 1485-1527.

[17] Pratt, J., D. Wise, and R. Zeckhauser, "Price Differences in Almost Competitive Markets," Quarterly Journal of Economics, (1979), Vol. 93, pp. 189-211.

[18] Radner, R., "Collusive Behavior in Oligopolies with Long But Finite Lives," Journal of Economic Theory, 22 (1980), 136-156. 
[19] Reinganum, Jennifer F., "A Simple Model of Equilibrium Price Dispersion," Journal of Political Economy (1979) 87, pp. 851-858.

[20] Rosenthal, Robert W., "A Model in Which an Increase in the Number of Sellers Leads to a Higher Price," Econometrica (1980) 48(6), pp. 1575-1580.

[21] Sorensen, Alan, "Equilibrium Price Dispersion in Retail Markets for Prescription Drugs," Journal Political Economy (2000), 108 (4), pp. 833-50.

[22] Spulber, Daniel F., "Bertrand Competition when Rivals' Costs are Unknown," Journal of Industrial Economics (1995), 43(1), pp. 1-11.

[23] Stahl, Dale O. II., "Strategic Advertising and Pricing in E-Commerce," Advances in Applied Microeconomics 9, (2000) 79, pp. 69-100.

[24] Stigler, G., "The Economics of Information," Journal of Political Economy 69 (1961), pp. 213-225.

[25] Varian, H., "A Model of Sales," American Economic Review (1980) 70, pp. 651659.

[26] Villas-Boas, J., "Models of Competitive Price Promotions: Some Empirical Evidence from the Coffee and Saltine Crackers Markets," Journal of Economics and Management Strategy 6 (1995), pp. 85-107.

[27] Warner, E. and R. Barsky, "The Timing and Magnitude of Retail Store Markdowns with Reference to Weekends and Holidays," Quarterly Journal of Economics, (1995), Vol. 110, pp. 321-52. 
Figure 1: Price Listings for an Epson Expression 1600 Professional Edition Scanner.

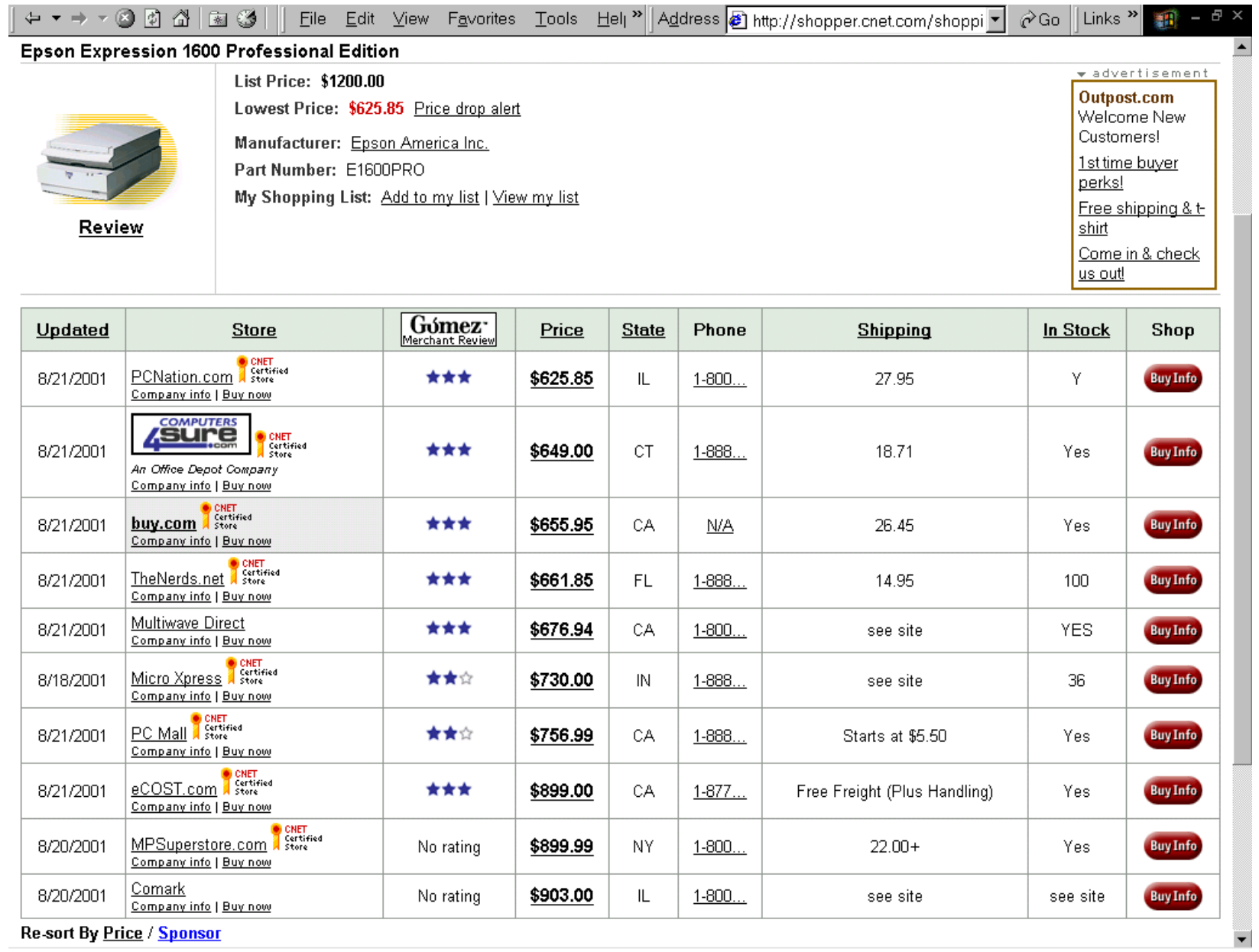

Data source: Shopper.com, August 21, 2001 
Figure 2: Interquartile Ranges of Prices in Duopoly Experiments with U.S. Subjects.

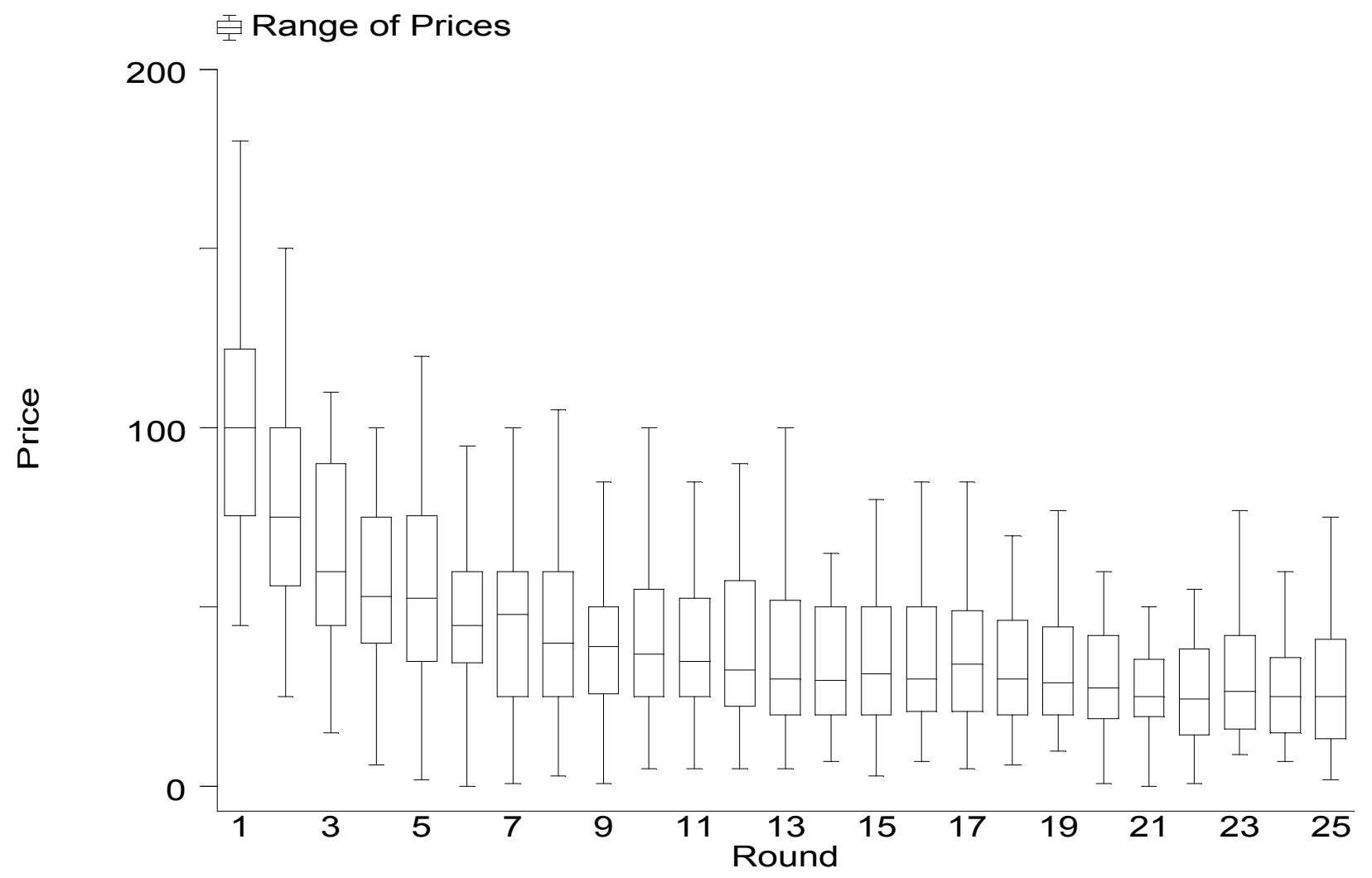

Data source: Abrams, Sefton and Yavas (1998). 
Figure 3: Cumulative Distributions of Prices under Nash and Random Behavior Compared to Actual Empirical Distribution of Prices: Duopoly Experiments with Dutch Subjects, All Rounds.

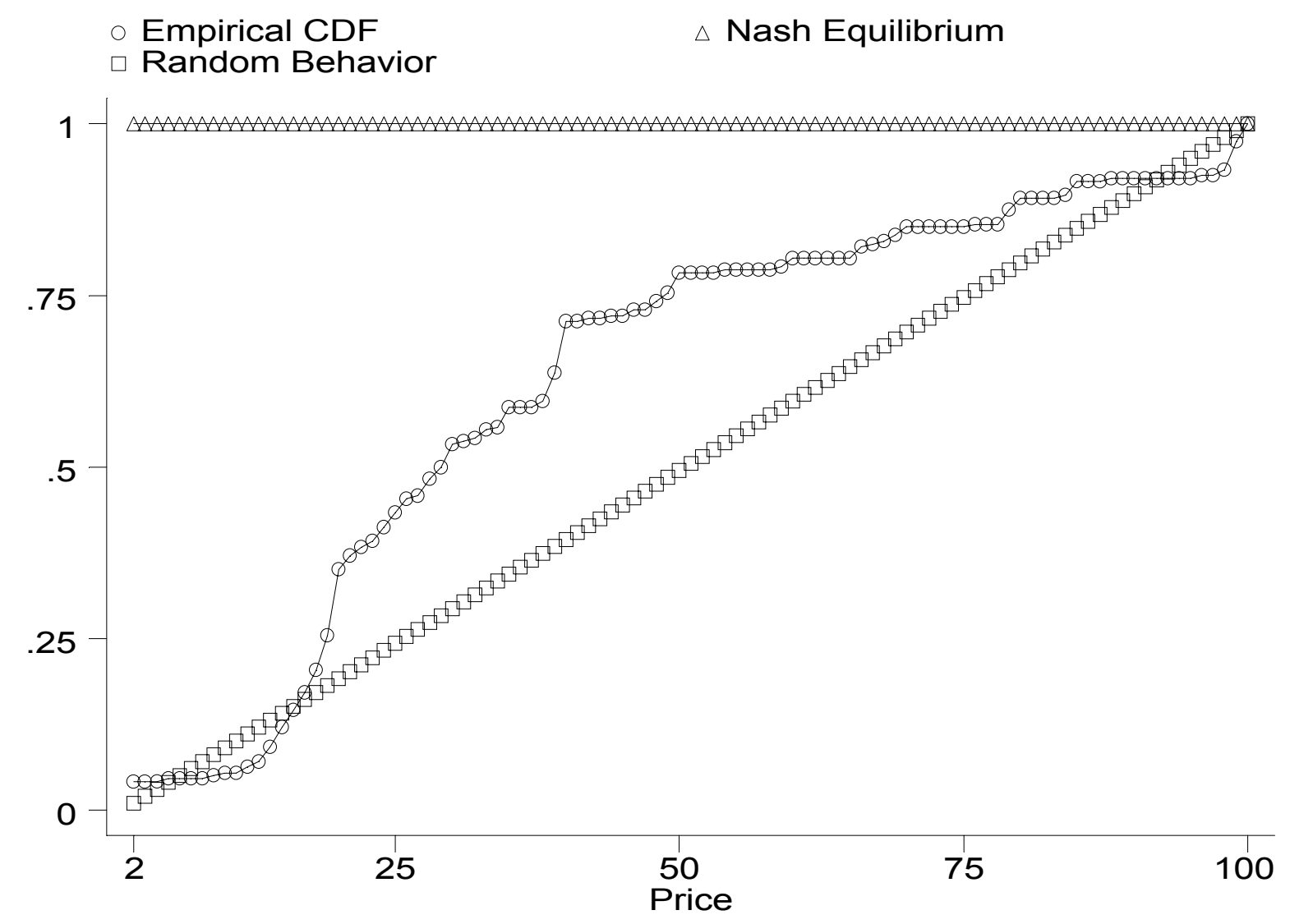

Data source: Dufwenberg and Gneezy (1998). 
Figure 4: Cumulative Distributions of Prices under Nash and Random Behavior Compared to Actual Empirical Distribution of Prices: Duopoly Experiments with US Subjects, All Rounds.

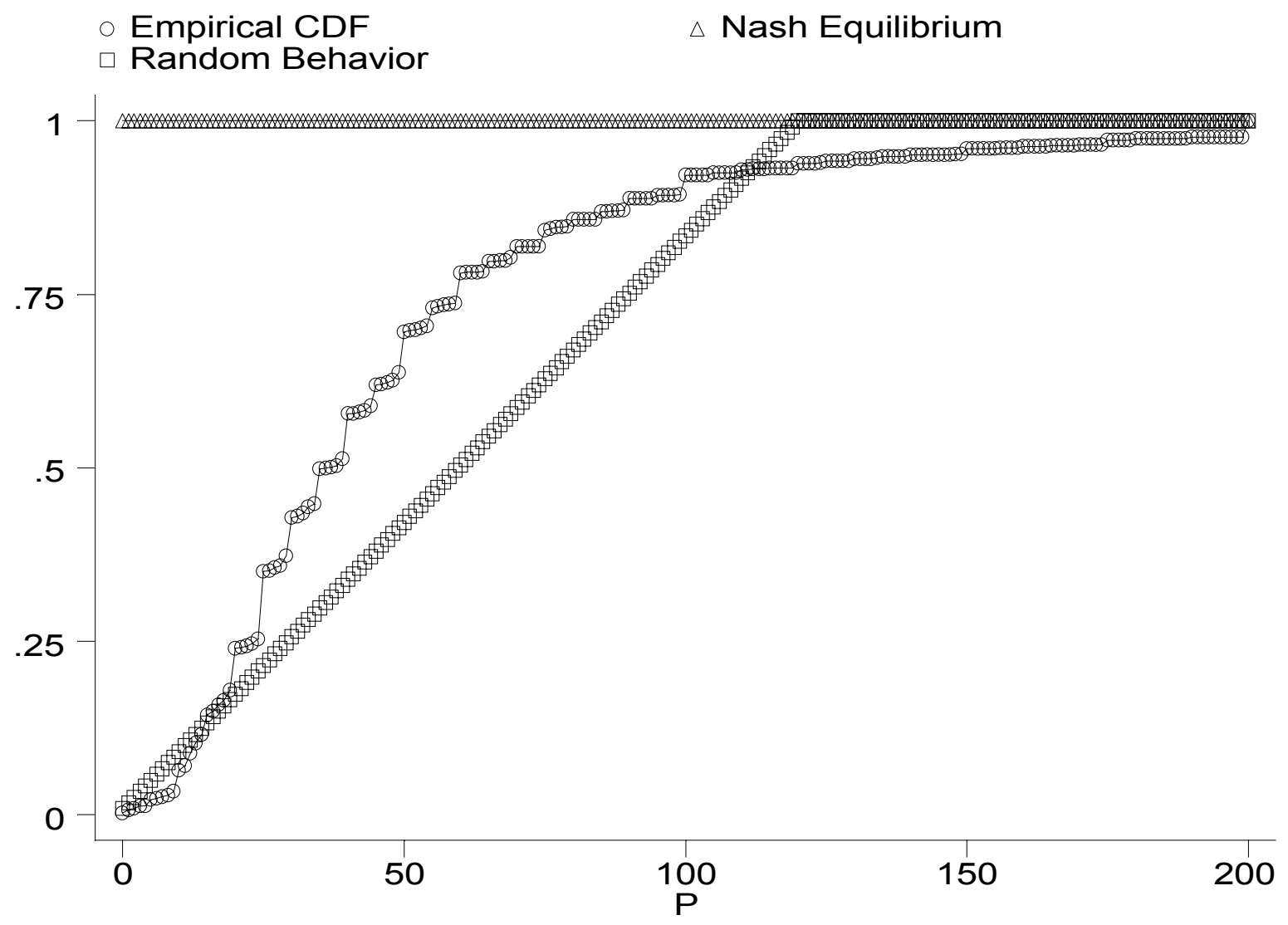

Data source: Abrams, Sefton and Yavas (1998). 
Figure 5: Cumulative Distributions of Prices under Nash and Random Behavior Compared to Actual Empirical Distribution of Prices: Triopoly Experiments with Dutch Subjects, All Rounds.

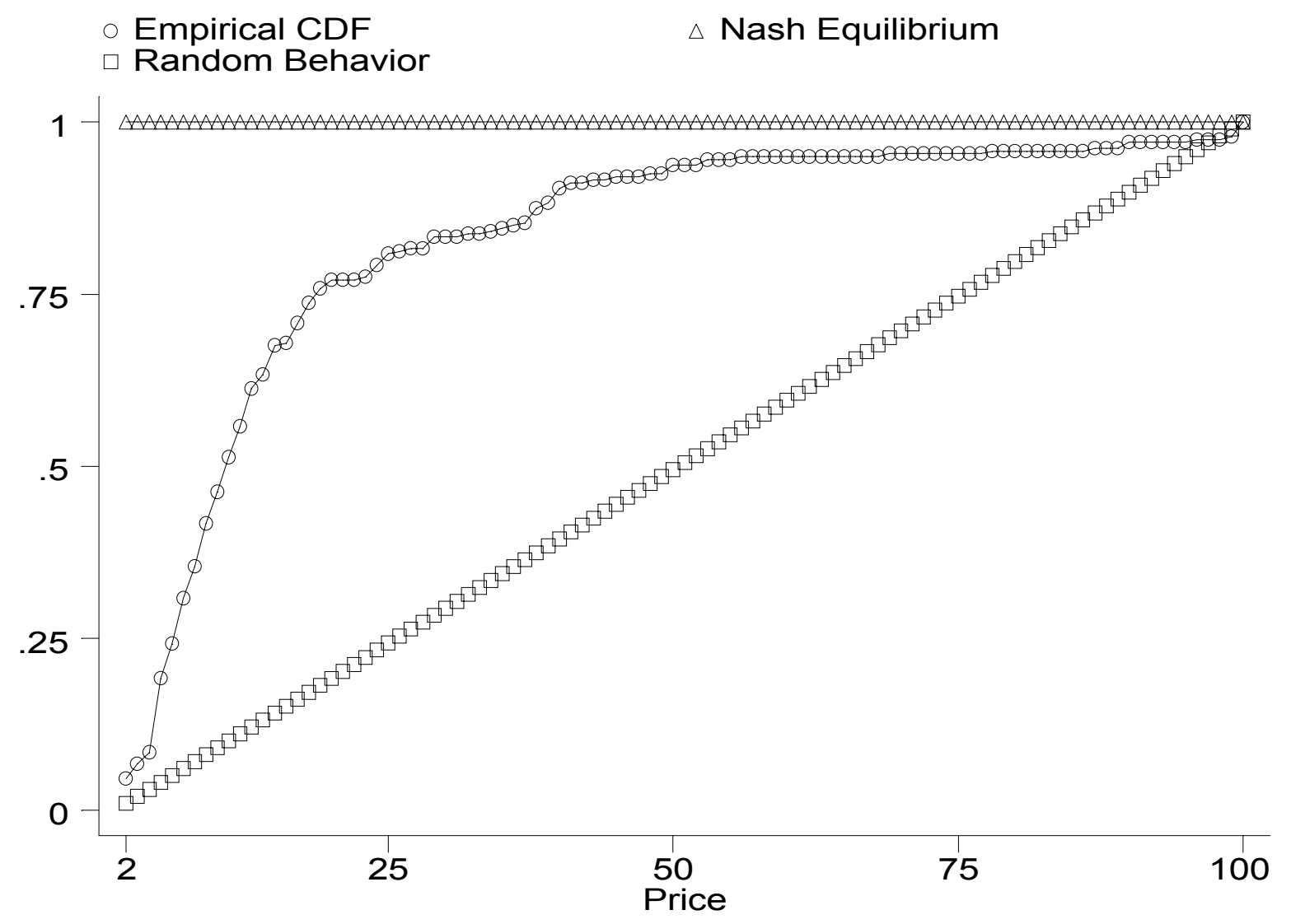

Data source: Dufwenberg and Gneezy (1998). 
Figure 6: Cumulative Distributions of Prices under Nash and Random Behavior Compared to Actual Empirical Distribution of Prices: Quadopoly Experiments with Dutch Subjects, All Rounds.

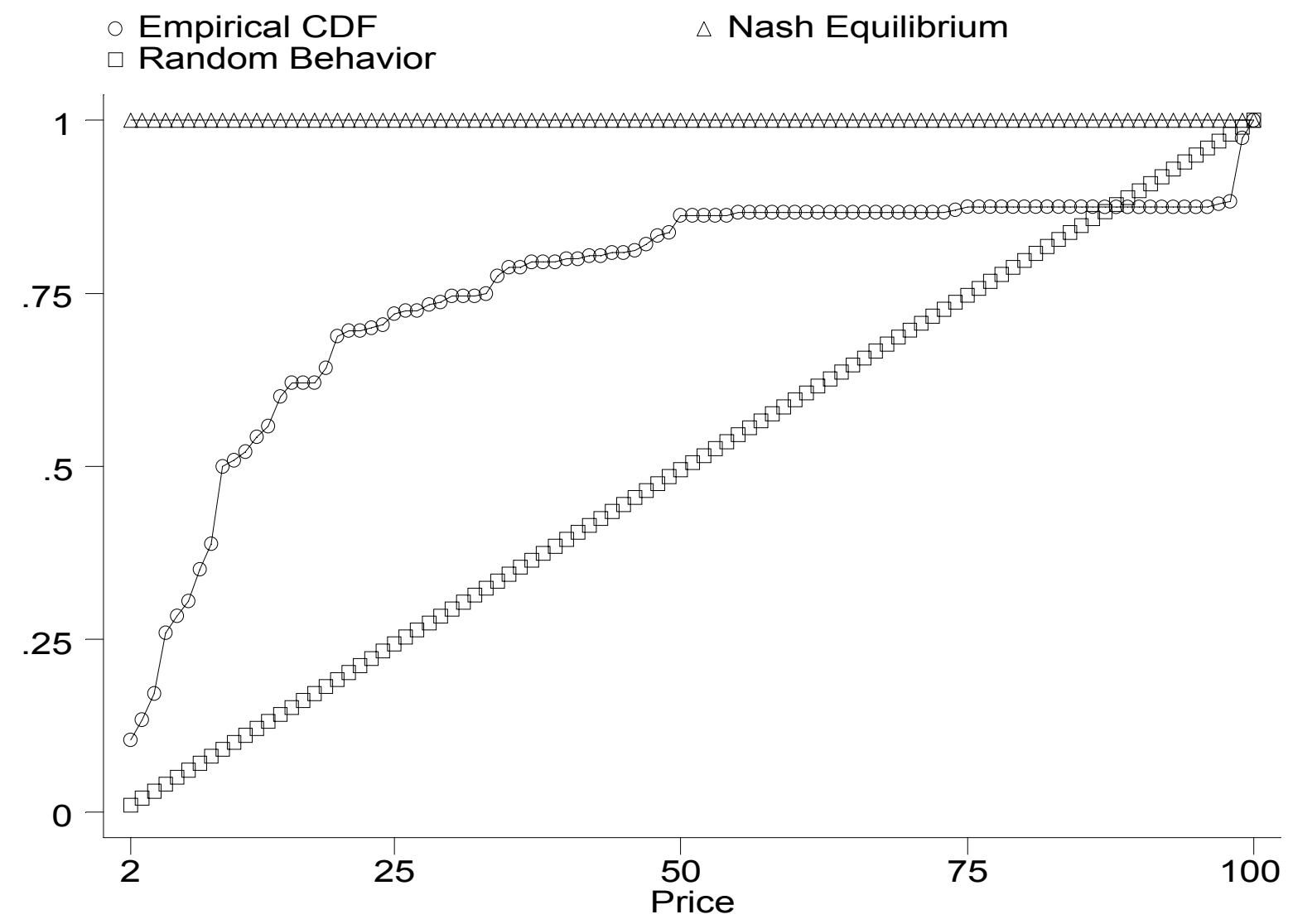

Data source: Dufwenberg and Gneezy (1998). 
Figure 7: Cumulative Distributions of Prices under Nash and Random Behavior Compared to Actual Empirical Distribution of Prices: Duopoly Experiments with Dutch Subjects, Last Round.

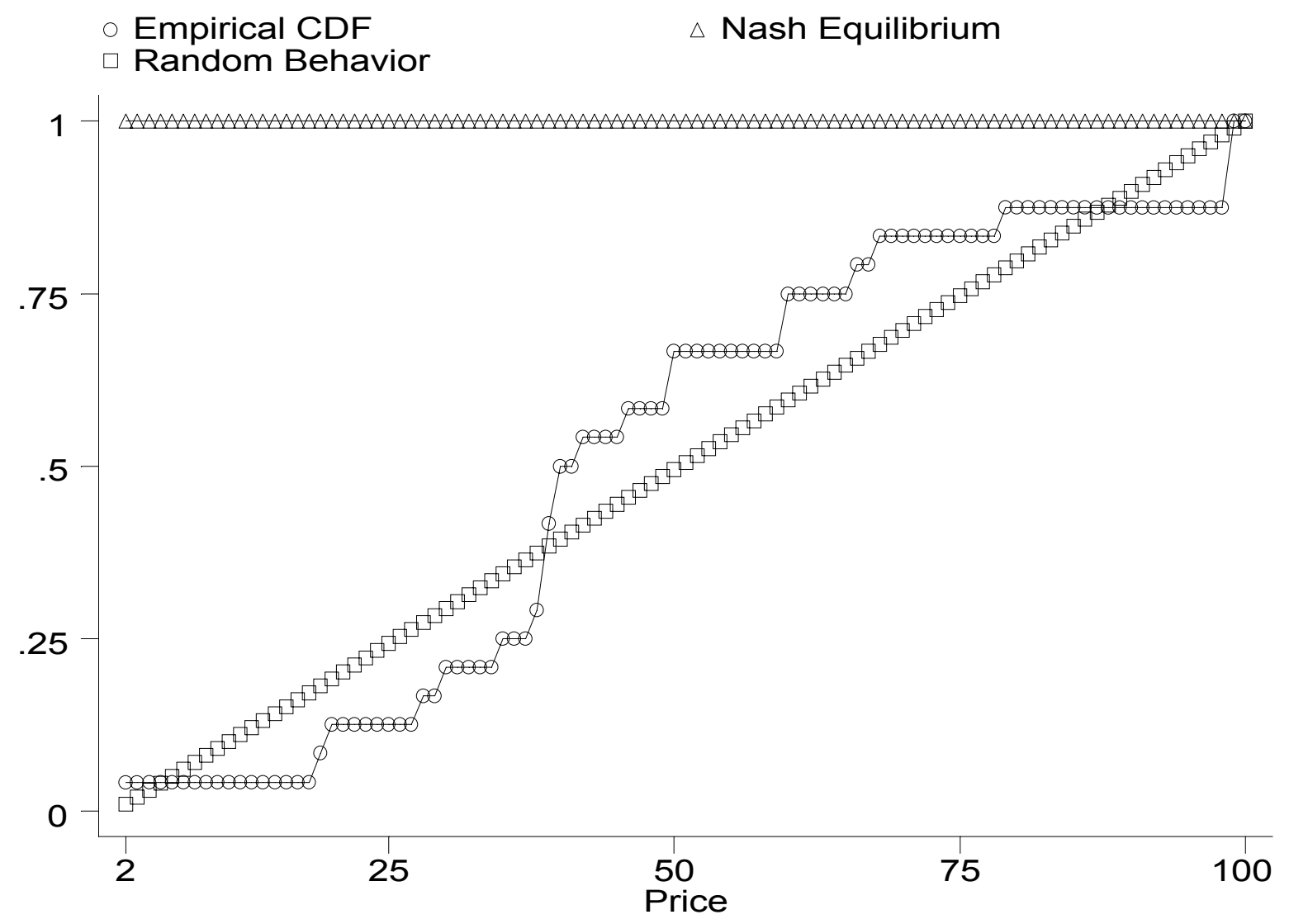

Data source: Dufwenberg and Gneezy (1998). 
Figure 8: Cumulative Distributions of Prices under Nash and Random Behavior Compared to Actual Empirical Distribution of Prices: Duopoly Experiments with US Subjects, Last Round.

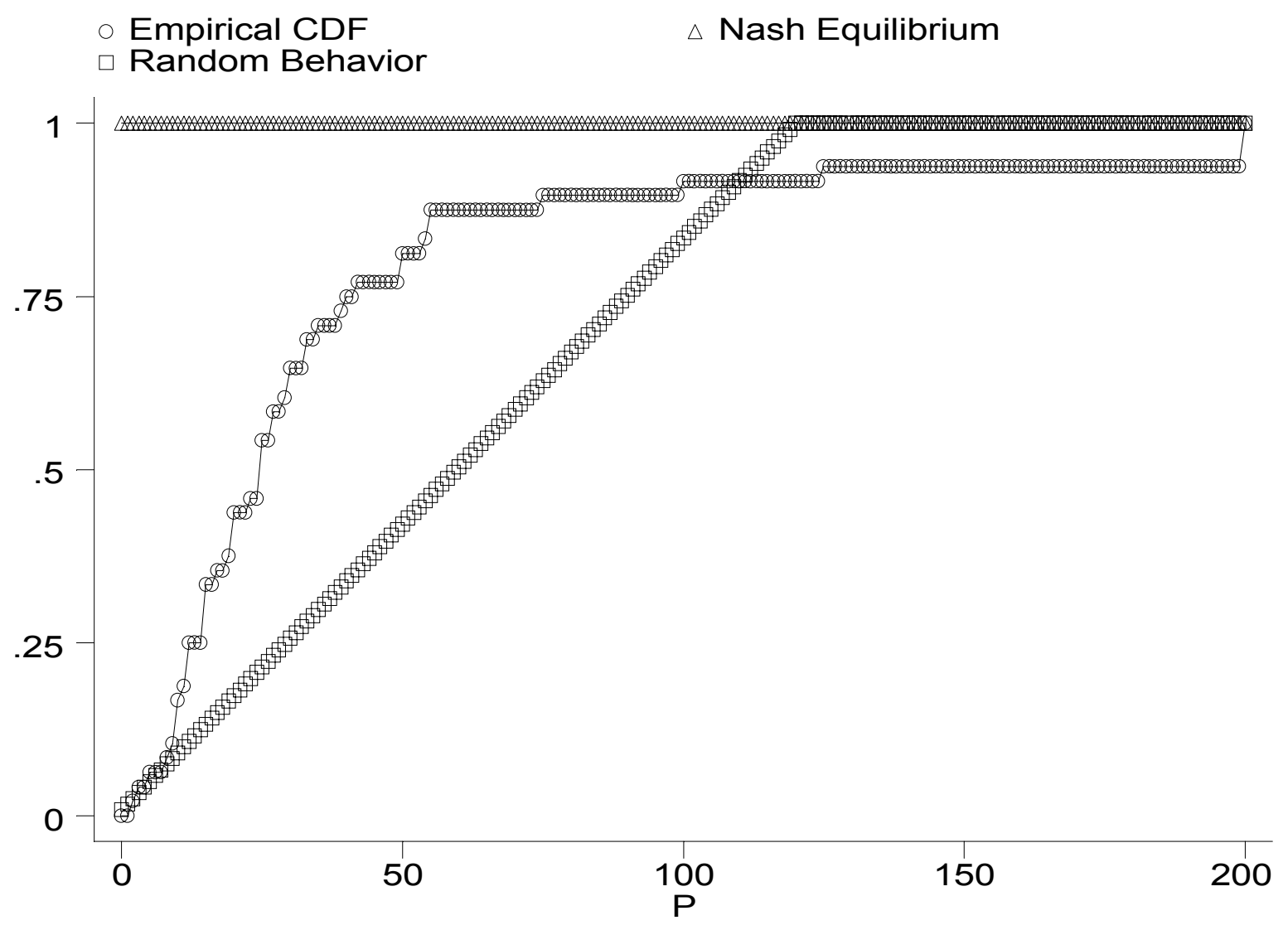

Data source: Abrams, Sefton and Yavas (1998). 
Figure 9: Cumulative Distributions of Prices under Nash and Random Behavior Compared to Actual Empirical Distribution of Prices: Triopoly Experiments with Dutch Subjects, Last Round.

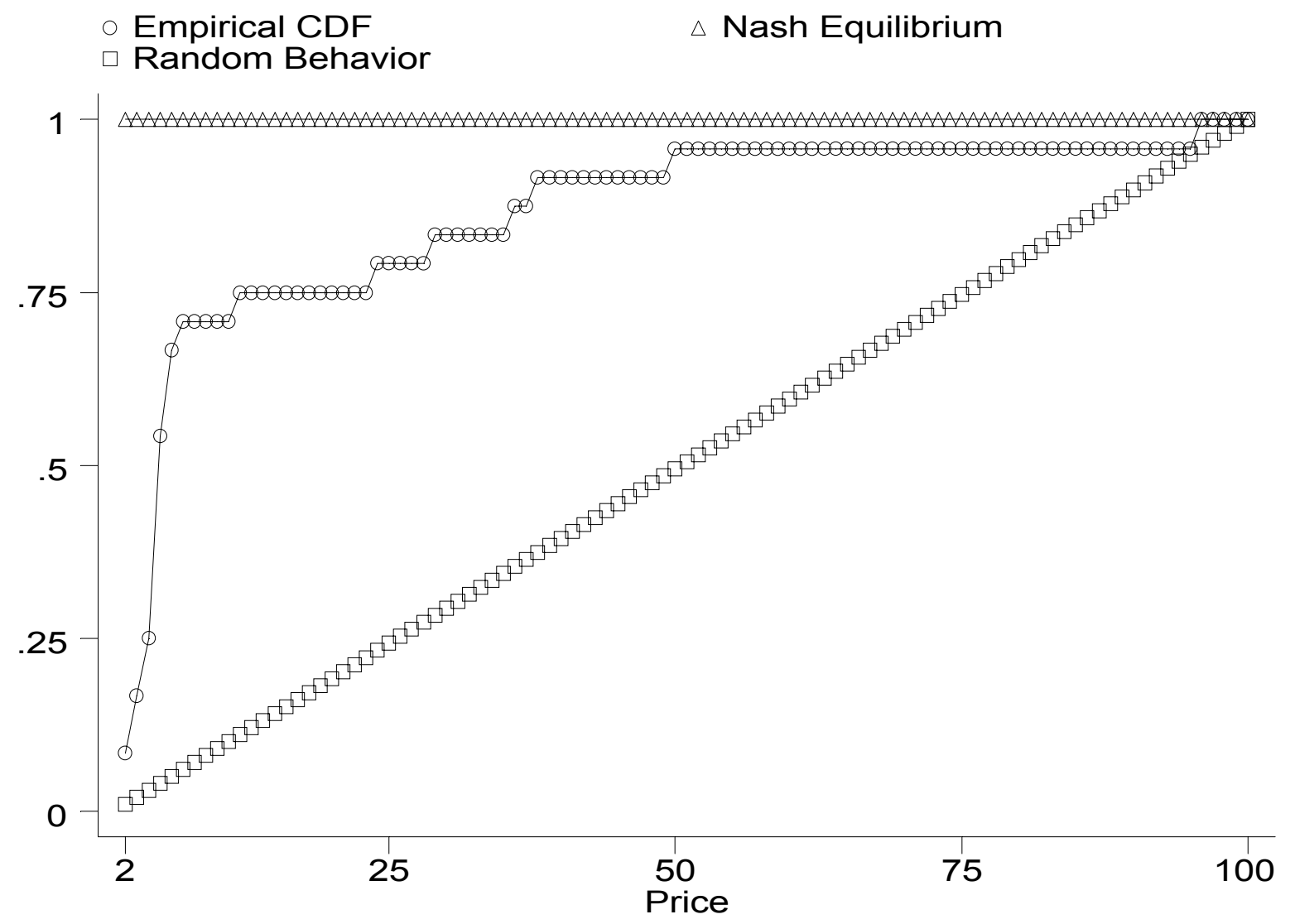

Data source: Dufwenberg and Gneezy (1998). 
Figure 10: Cumulative Distributions of Prices under Nash and Random Behavior Compared to Actual Empirical Distribution of Prices: Quadopoly Experiments with Dutch Subjects, Last Round.

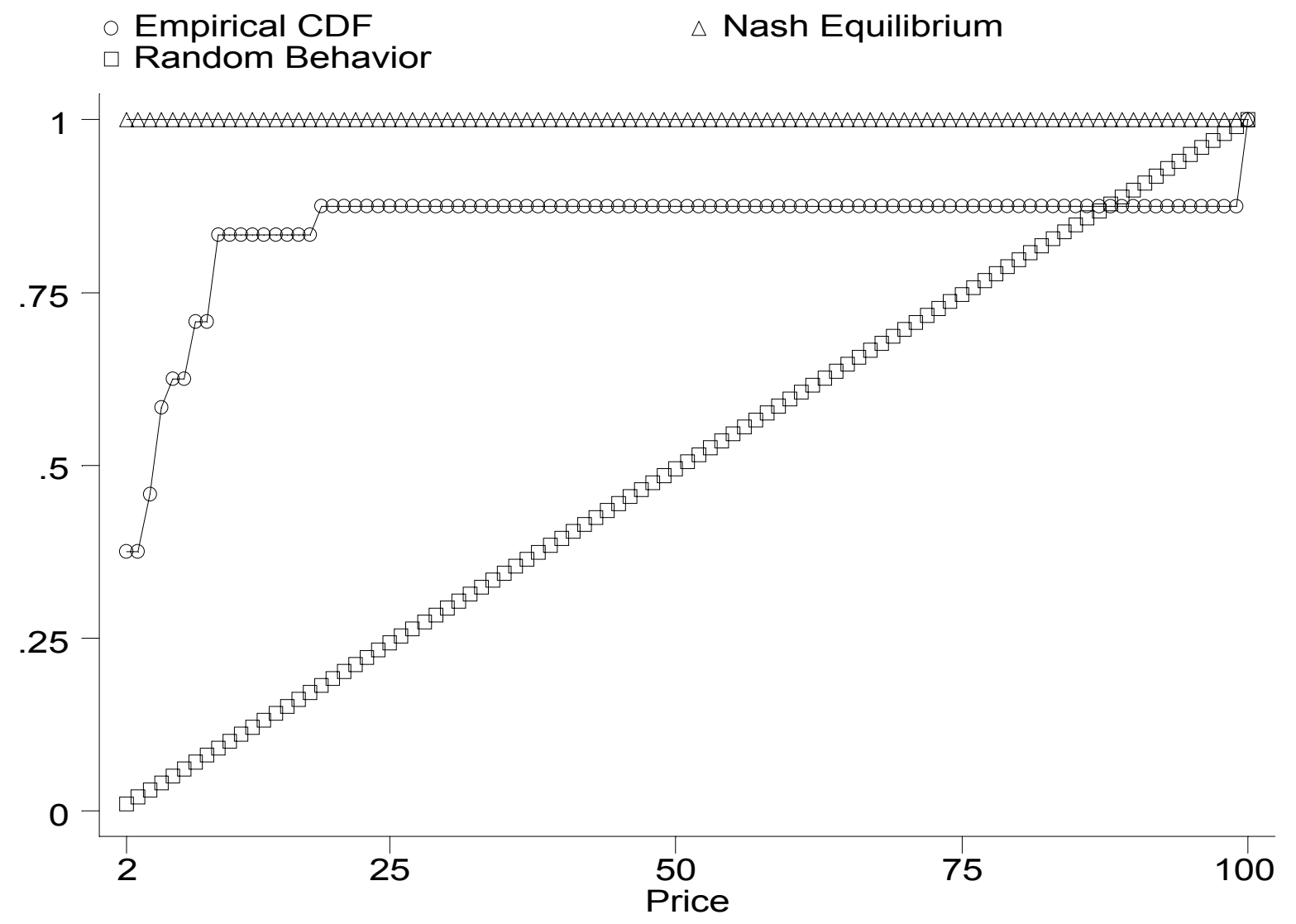

Data source: Dufwenberg and Gneezy (1998). 
Figure 11: Cumulative Distributions of Prices under QRE and Epsilon Equilibrium Compared to Actual Empirical Distribution of Prices: Duopoly Experiments with Dutch Subjects, All Rounds.

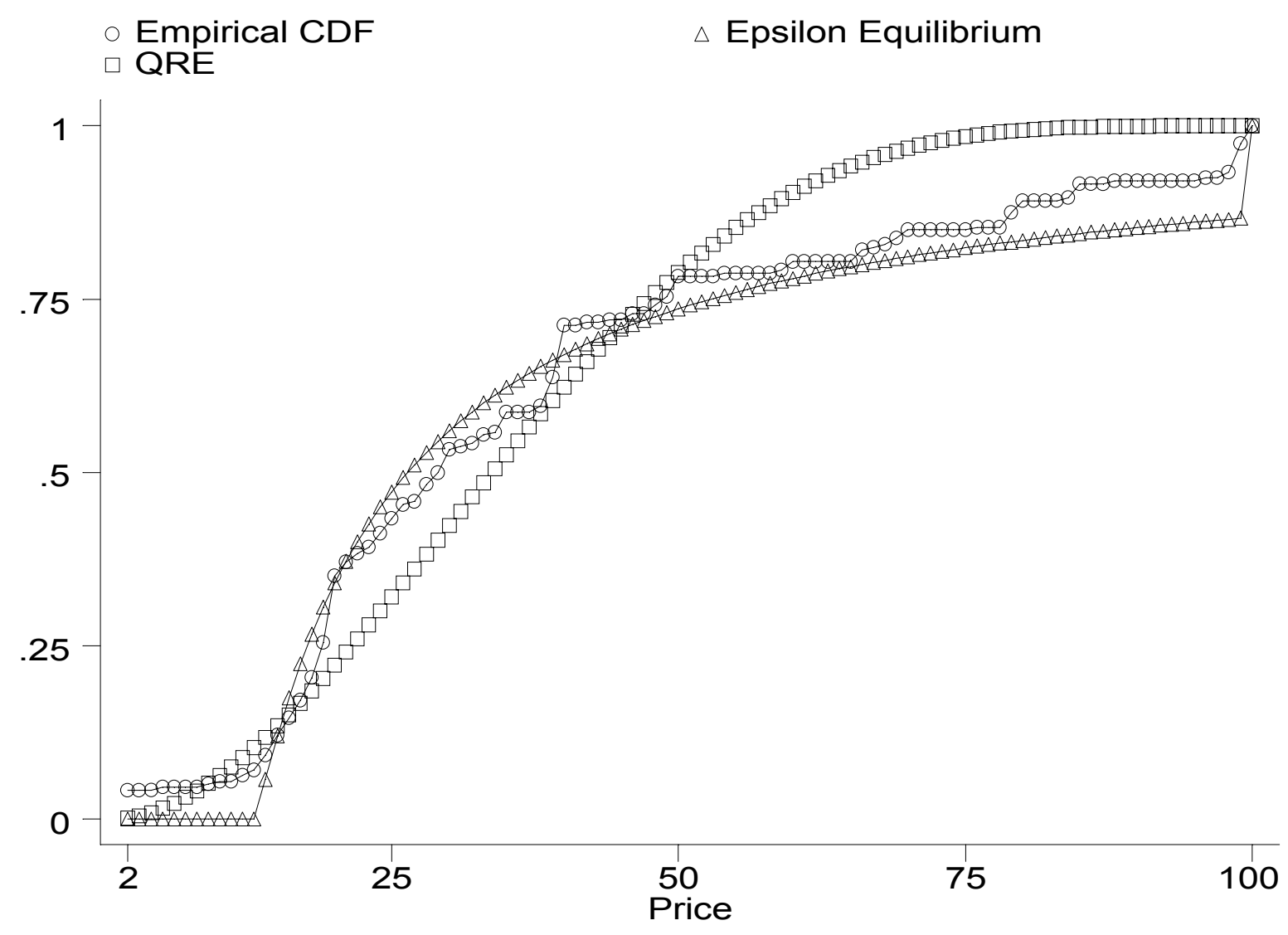

Data source: Dufwenberg and Gneezy (1998). 
Figure 12: Cumulative Distributions of Prices under QRE and Epsilon Equilibrium Compared to Actual Empirical Distribution of Prices: Duopoly Experiments with US Subjects, All Rounds.

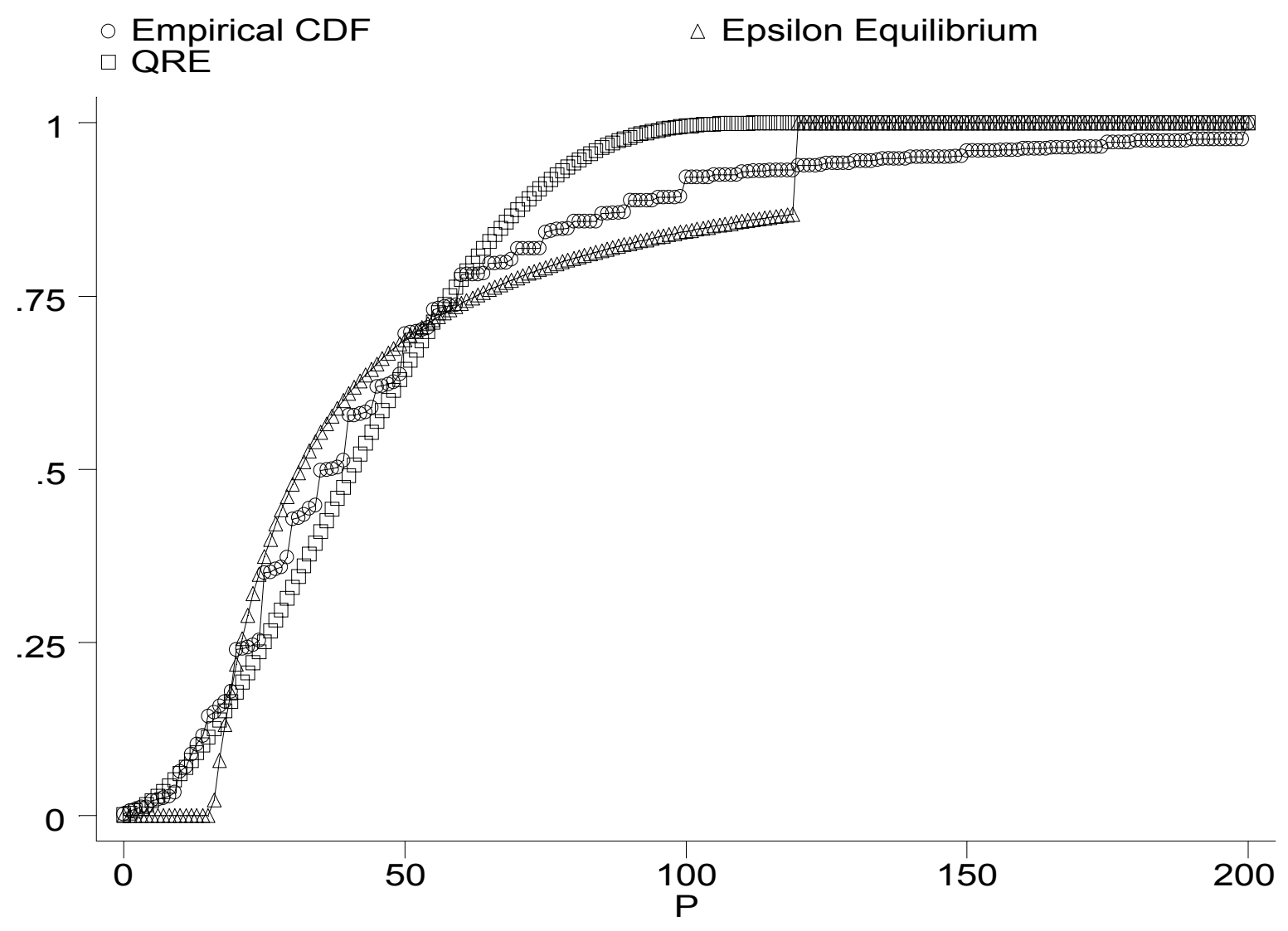

Data source: Abrams, Sefton and Yavas (1998). 
Figure 13: Cumulative Distributions of Prices under QRE and Epsilon Equilibrium Compared to Actual Empirical Distribution of Prices: Triopoly Experiments with Dutch Subjects, All Rounds.

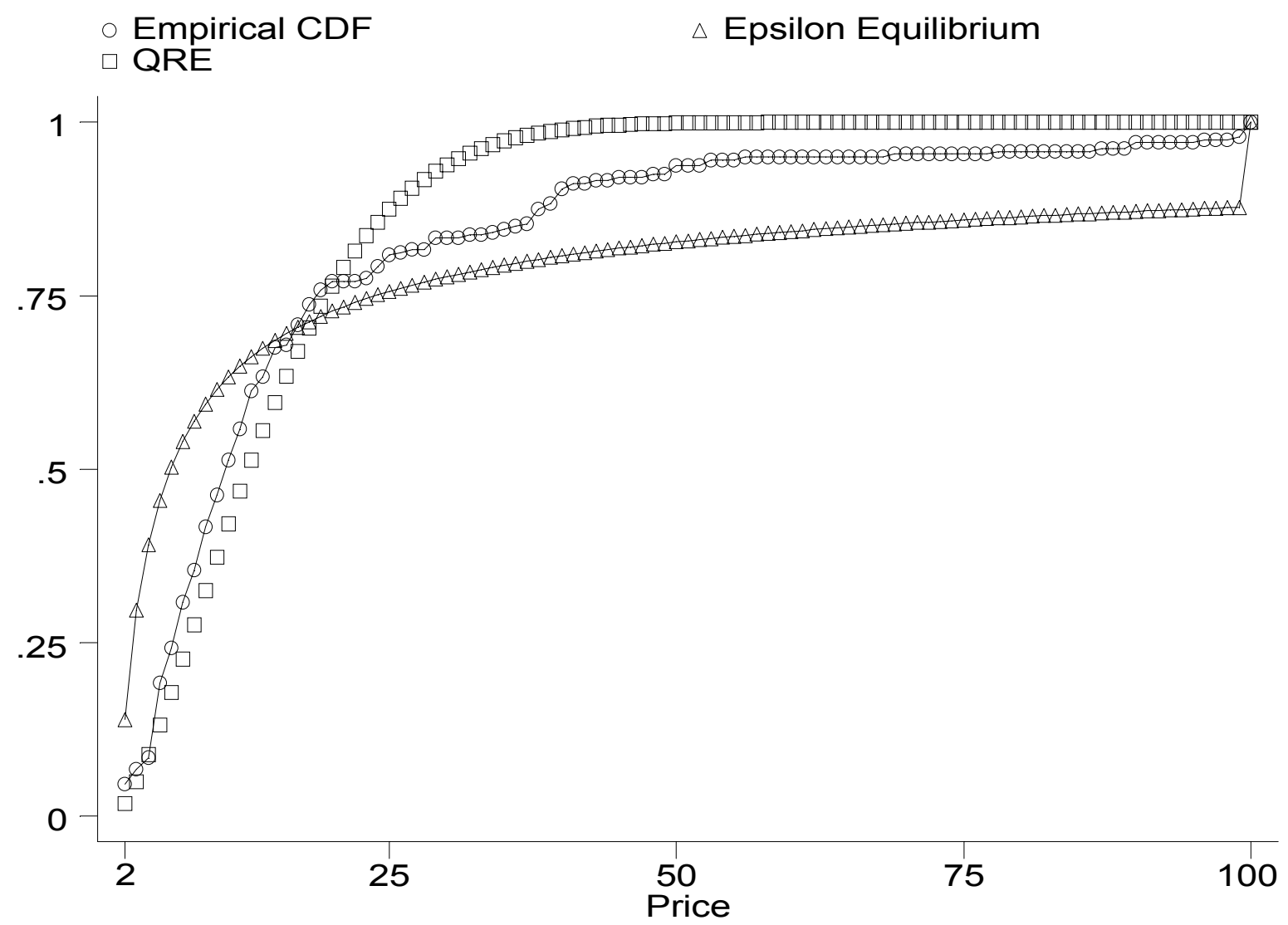

Data source: Dufwenberg and Gneezy (1998). 
Figure 14: Cumulative Distributions of Prices under QRE and Epsilon Equilibrium Compared to Actual Empirical Distribution of Prices: Quadopoly Experiments with Dutch Subjects, All Rounds.

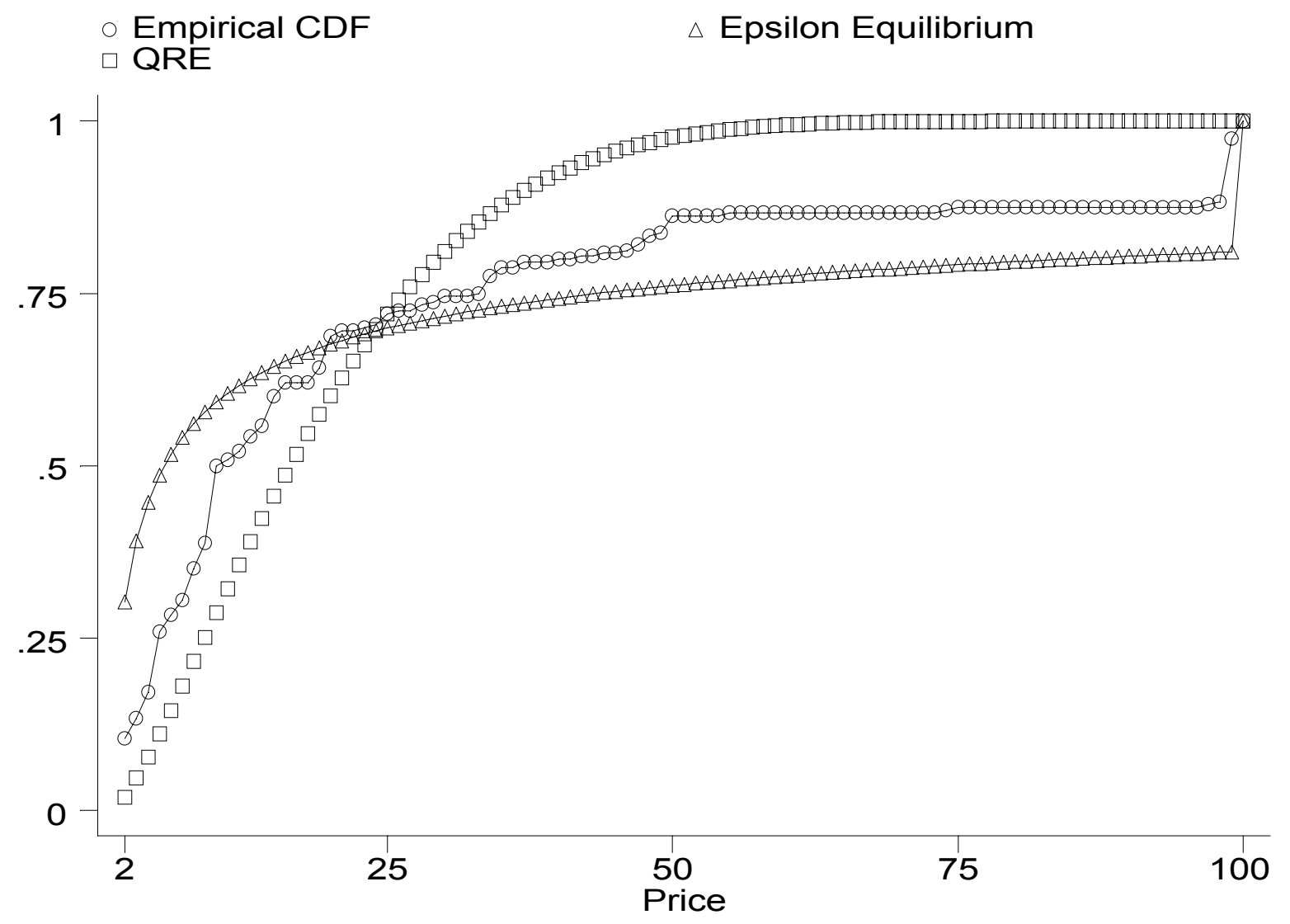

Data source: Dufwenberg and Gneezy (1998). 
Figure 15: Cumulative Distributions of Prices under QRE and Epsilon Equilibrium Compared to Actual Empirical Distribution of Prices: Duopoly Experiments with Dutch Subjects, Last Round.

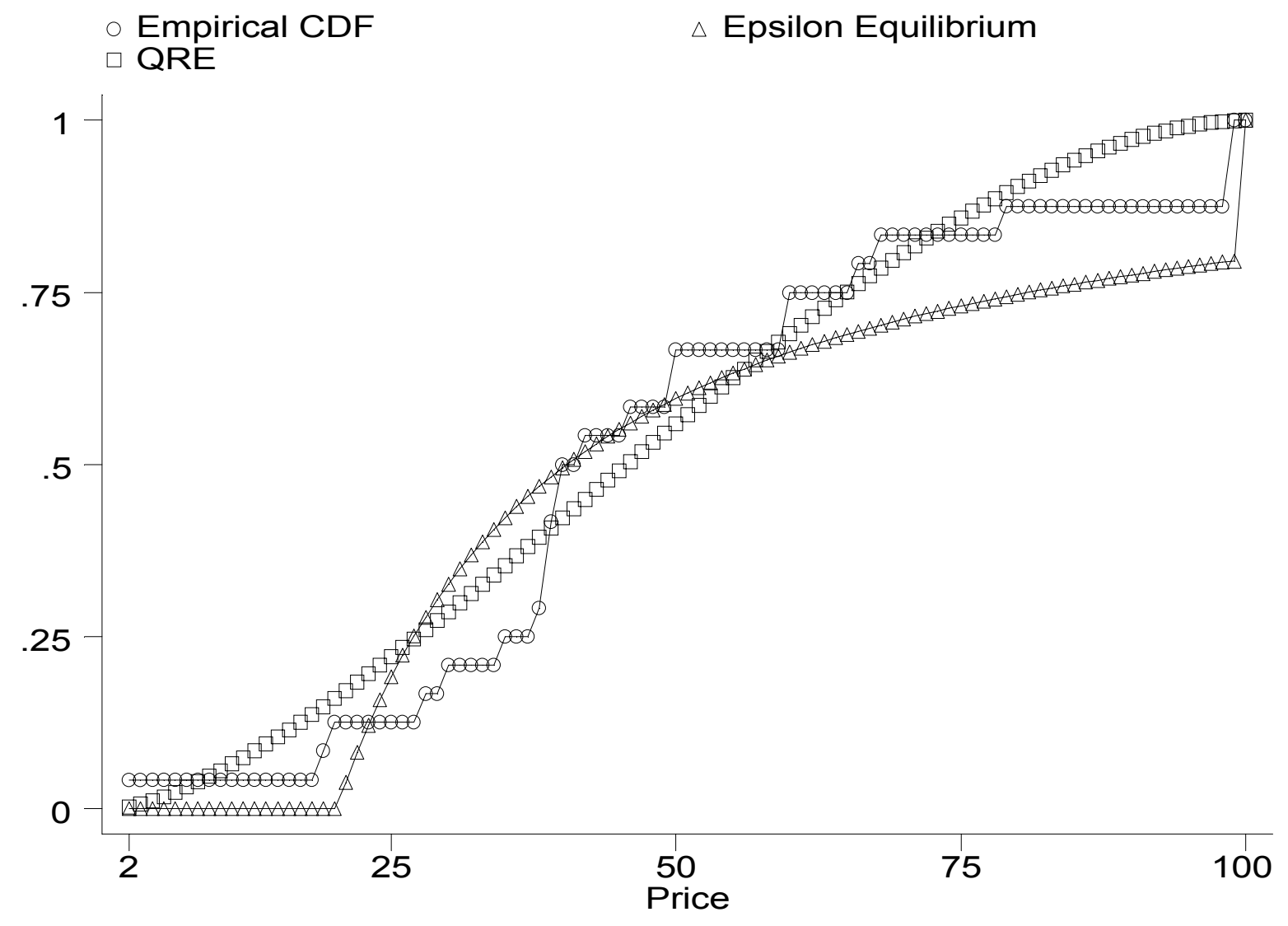

Data source: Dufwenberg and Gneezy (1998). 
Figure 16: Cumulative Distributions of Prices under QRE and Epsilon Equilibrium Compared to Actual Empirical Distribution of Prices: Duopoly Experiments with US Subjects, Last Round.

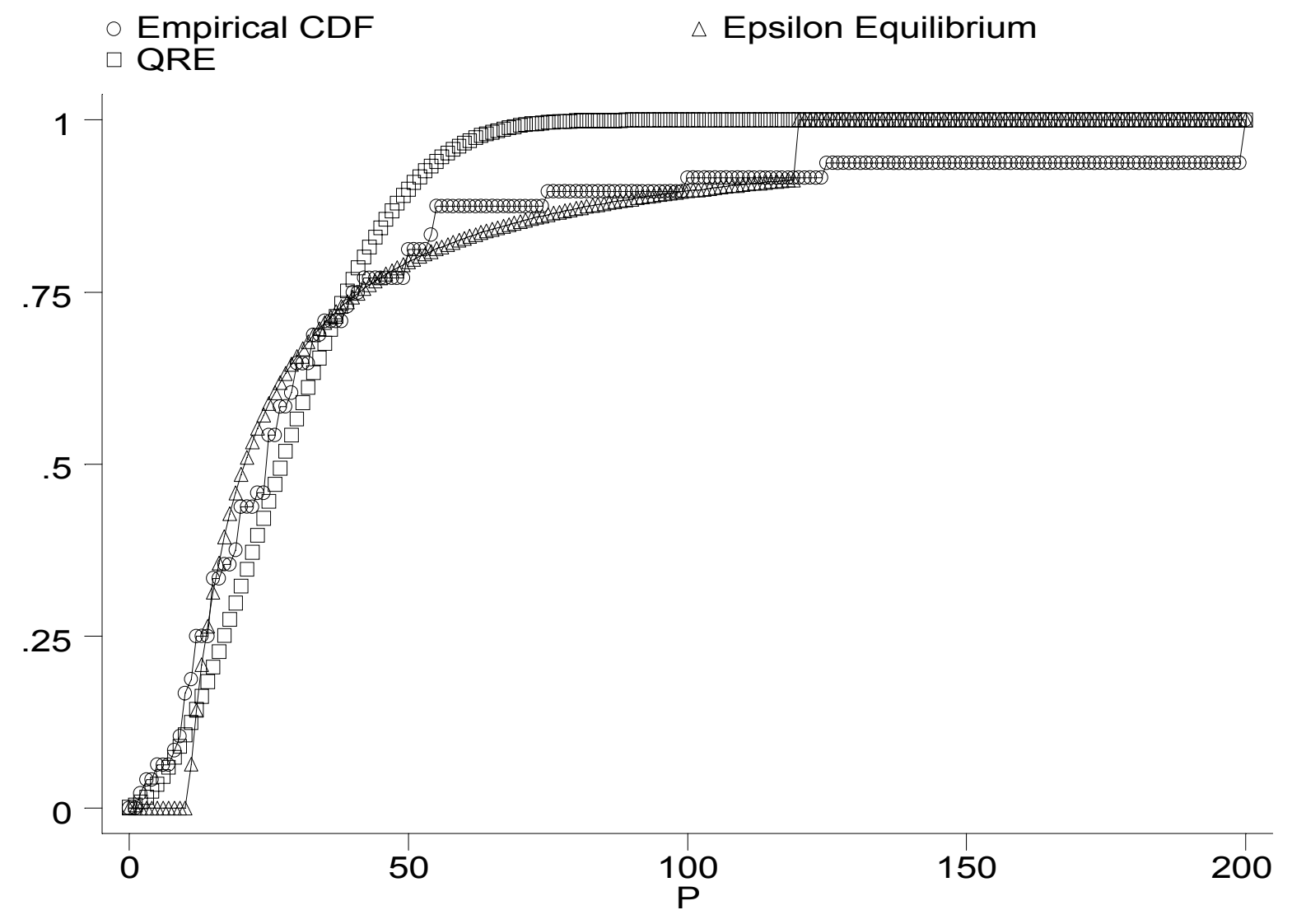

Data source: Abrams, Sefton and Yavas (1998). 
Figure 17: Cumulative Distributions of Prices under QRE and Epsilon Equilibrium Compared to Actual Empirical Distribution of Prices: Triopoly Experiments with Dutch Subjects, Last Round.

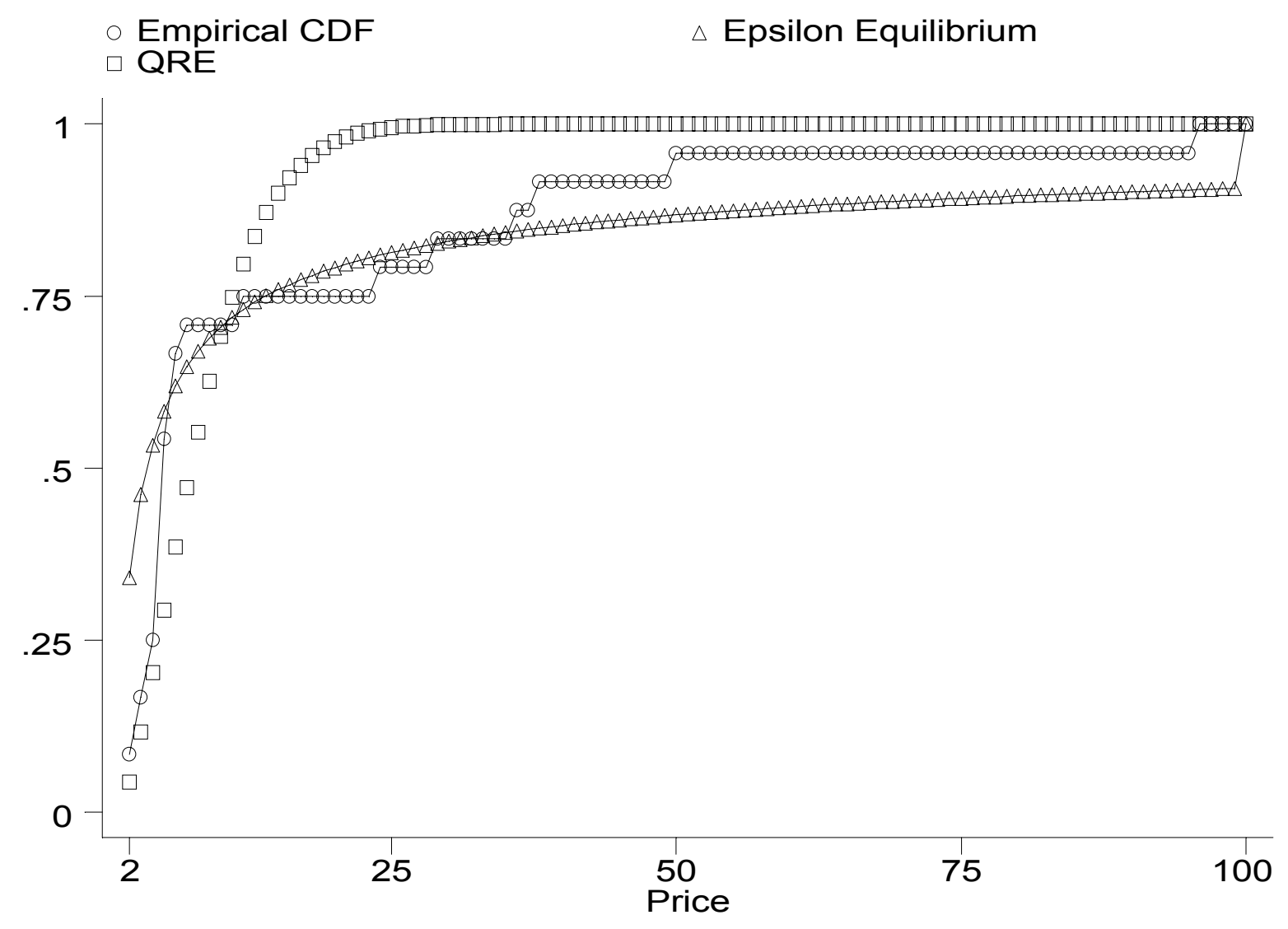

Data source: Dufwenberg and Gneezy (1998). 
Figure 18: Cumulative Distributions of Prices under QRE and Epsilon Equilibrium Compared to Actual Empirical Distribution of Prices: Quadopoly Experiments with Dutch Subjects, Last Round.

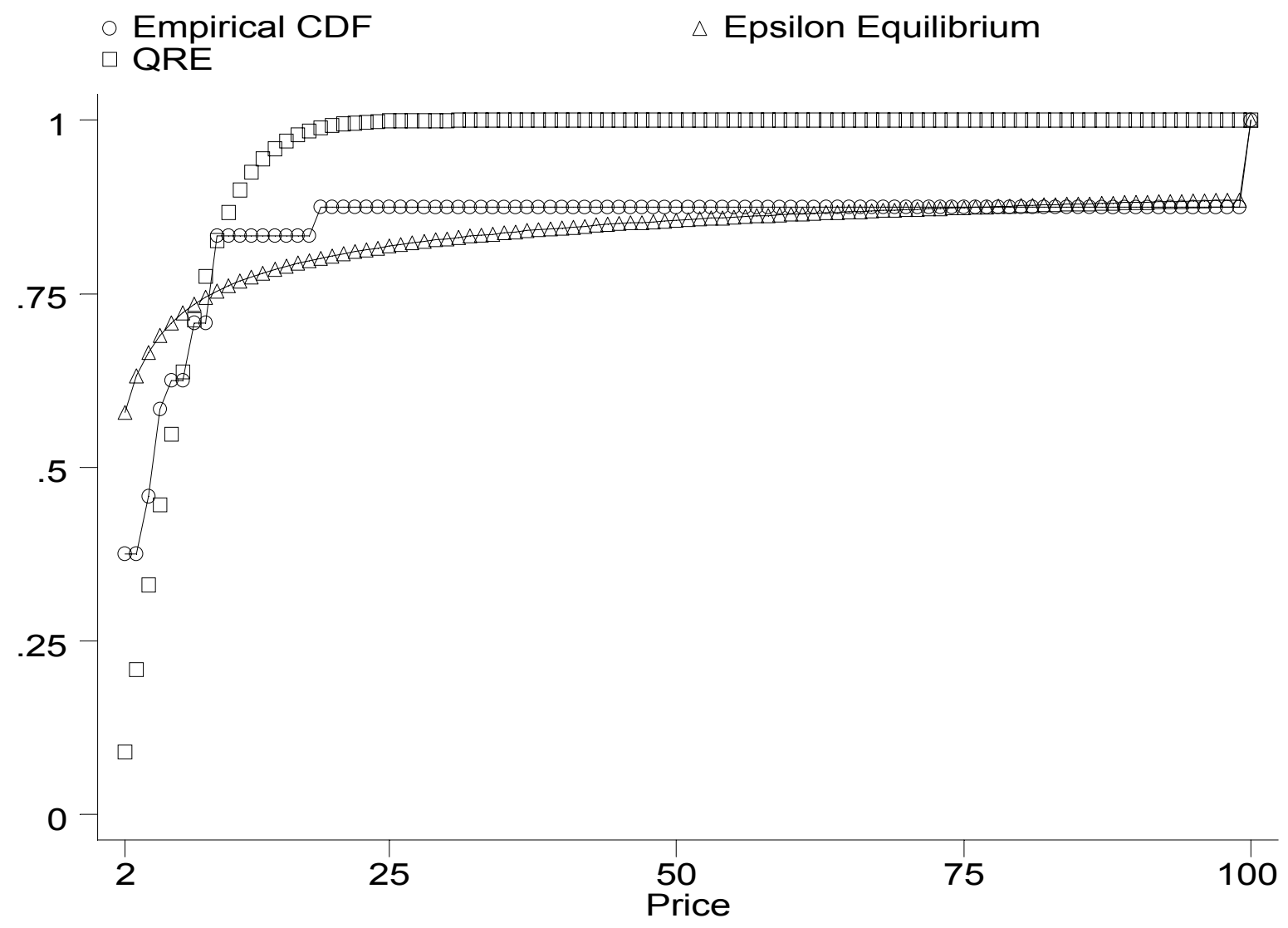

Data source: Dufwenberg and Gneezy (1998). 
Figure 19: Observed Relationship between CV and Number of Firms Listing Prices on the Internet

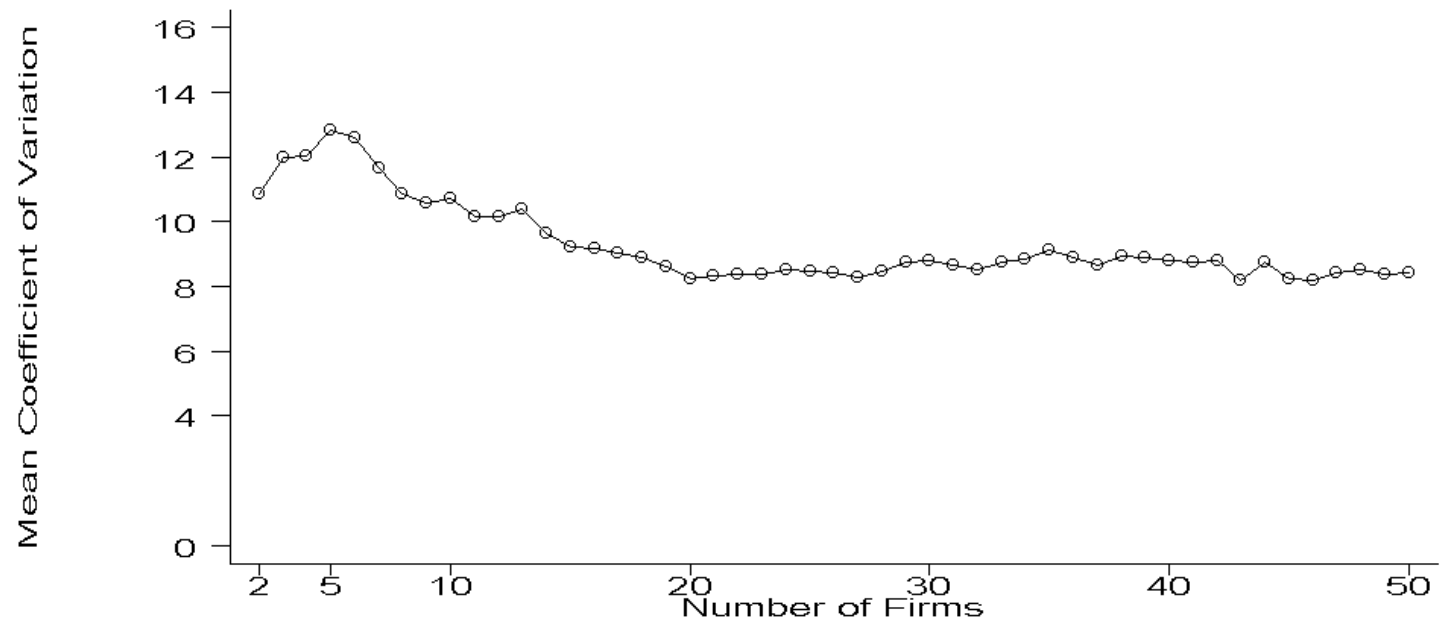

Data Source: Baye, Morgan, and Scholten (2001a).

Figure 20: Theoretical Relationship between CV and Number of Firms for Epsilon $=1 \mathrm{c}$

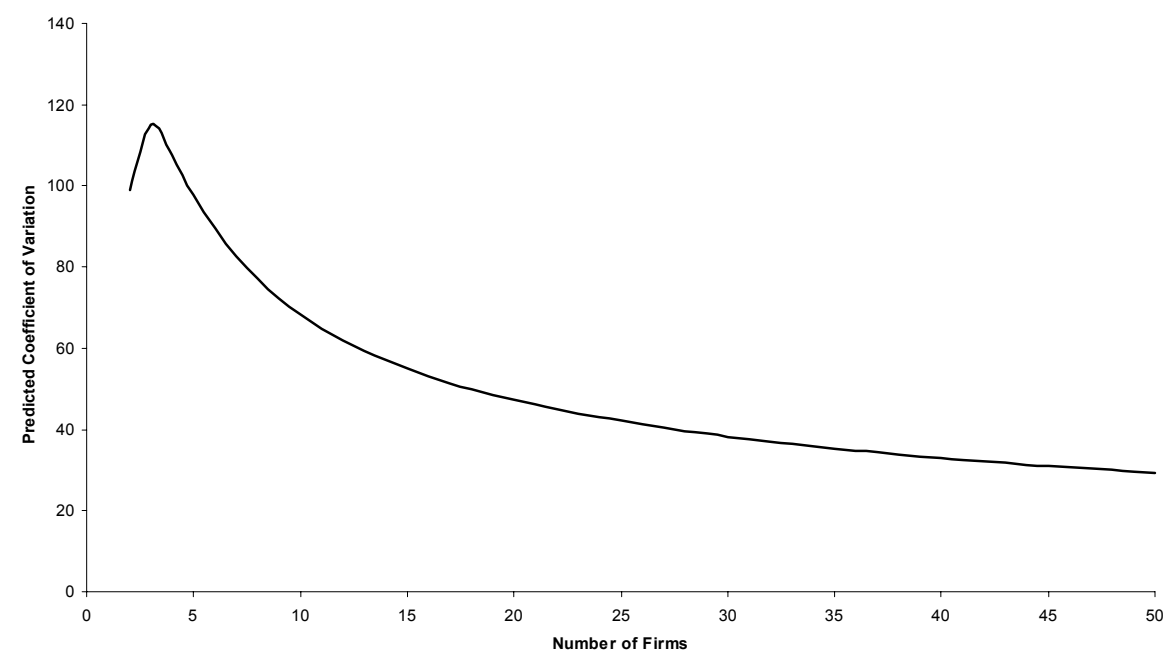

Note: Computations based on epsilon equilibrium with zero costs and unit demand up to a price of $\$ 2.98$. 
Table 1: Price Dispersion on the Internet

\begin{tabular}{|c|c|c|c|c|c|c|}
\hline Product & $\begin{array}{l}\text { Coefficient } \\
\text { of Variation }\end{array}$ & $\begin{array}{l}\text { Price } \\
\text { Range }\end{array}$ & $\begin{array}{c}\text { Average } \\
\text { Price }\end{array}$ & $\begin{array}{c}\text { Lowest } \\
\text { Price }\end{array}$ & $\begin{array}{c}\text { Number } \\
\text { of } \\
\text { Sellers }\end{array}$ & $\begin{array}{c}\text { Product } \\
\text { Rank }\end{array}$ \\
\hline Sony VAIO PCG_XG28 (Pentium III 650 MHz, 128MB RAM, 12.0GB) & $28.5 \%$ & $\$ 1,607.00$ & $\$ 2,150.70$ & $\$ 1,592.00$ & 10 & 43 \\
\hline Palm IIle & $23.9 \%$ & $\$ 80.99$ & $\$ 162.24$ & $\$ 139.00$ & 4 & 19 \\
\hline HP Pavilion 6736c Multimedia PC (Celeron 667MHz, 64 MB SDRAM, 20 & $22.9 \%$ & $\$ 164.00$ & $\$ 507.00$ & $\$ 425.00$ & 2 & 33 \\
\hline Kodak DC280 Zoom & $22.5 \%$ & $\$ 279.01$ & $\$ 433.65$ & $\$ 319.99$ & 8 & 10 \\
\hline Iomega Zip USB 100MB External Zip Drive & $18.9 \%$ & $\$ 53.39$ & $\$ 87.66$ & $\$ 66.56$ & 17 & 82 \\
\hline Xircom Rex 6000 & $16.7 \%$ & $\$ 89.01$ & $\$ 149.28$ & $\$ 99.99$ & 12 & 90 \\
\hline Kingston 128MB DRAM DIMM 168_PIN & $16.7 \%$ & $\$ 27.05$ & $\$ 50.52$ & $\$ 41.95$ & 21 & 59 \\
\hline Sony 64MB Flash Memory Stick & $15.6 \%$ & $\$ 59.00$ & $\$ 116.04$ & $\$ 90.99$ & 27 & 54 \\
\hline Abit KT7 (Socket A) & $15.3 \%$ & $\$ 51.53$ & $\$ 143.91$ & $\$ 128.00$ & 5 & 34 \\
\hline 256MB PC 100 SDRAM & $15.0 \%$ & $\$ 29.12$ & $\$ 78.75$ & $\$ 65.88$ & 10 & 24 \\
\hline C_3040 ZOOM DIGTLCAM 3.34MPIX 16MB 3X OPT ZOOM & $14.5 \%$ & $\$ 321.49$ & $\$ 886.22$ & $\$ 689.99$ & 24 & 69 \\
\hline Office 2000 _ Professional Edition & $14.4 \%$ & $\$ 208.00$ & $\$ 482.62$ & $\$ 349.00$ & 31 & 88 \\
\hline Olympus C_3030 Zoom & $14.4 \%$ & $\$ 376.00$ & $\$ 774.12$ & $\$ 623.00$ & 50 & 6 \\
\hline Canon PowerShot S10 & $14.0 \%$ & $\$ 174.99$ & $\$ 427.64$ & $\$ 325.00$ & 30 & 91 \\
\hline Abit KT7A (Socket A) & $12.6 \%$ & $\$ 54.89$ & $\$ 146.29$ & $\$ 132.00$ & 8 & 89 \\
\hline Asus P4T (Pentium 4 Motherboard) & $12.2 \%$ & $\$ 69.05$ & $\$ 221.80$ & $\$ 189.95$ & 9 & 71 \\
\hline Palm V & $11.7 \%$ & $\$ 81.24$ & $\$ 355.54$ & $\$ 318.75$ & 5 & 7 \\
\hline Olympus D_460 Zoom & $11.6 \%$ & $\$ 139.00$ & $\$ 322.61$ & $\$ 260.00$ & 43 & 64 \\
\hline D_Link MP3/CD Player & $11.5 \%$ & $\$ 45.05$ & $\$ 102.18$ & $\$ 89.90$ & 21 & 72 \\
\hline Palm IIIxe & $11.3 \%$ & $\$ 74.01$ & $\$ 190.16$ & $\$ 164.99$ & 27 & 11 \\
\hline Olympus D_490 Zoom & $11.2 \%$ & $\$ 165.01$ & $\$ 416.37$ & $\$ 333.99$ & 45 & 21 \\
\hline Kodak DC3400 & $11.2 \%$ & $\$ 146.00$ & $\$ 355.11$ & $\$ 293.00$ & 44 & 53 \\
\hline Palm VIIx & $10.9 \%$ & $\$ 152.00$ & $\$ 364.80$ & $\$ 297.00$ & 44 & 74 \\
\hline 128MB 16X64 SDRAM PC133 8NS & $10.9 \%$ & $\$ 13.11$ & $\$ 40.92$ & $\$ 35.88$ & 10 & 23 \\
\hline VirusScan 5.0: Win3.x/9X/NT351, OS/2, DOS & $10.7 \%$ & $\$ 8.73$ & $\$ 27.84$ & $\$ 24.19$ & 11 & 67 \\
\hline Epson Stylus Photo 1270 & $10.5 \%$ & $\$ 166.00$ & $\$ 384.38$ & $\$ 333.99$ & 35 & 45 \\
\hline Compaq iPaq H3650 Pocket PC & $10.5 \%$ & $\$ 169.71$ & $\$ 565.68$ & $\$ 490.28$ & 29 & 1 \\
\hline Kingston 256MB DRAM DIMM 168_PIN & $10.3 \%$ & $\$ 30.05$ & $\$ 95.54$ & $\$ 84.95$ & 20 & 62 \\
\hline Sony VAIO PCG_XG29 (Pentium III 750 MHz, 128MB RAM, 18GB) & $10.0 \%$ & $\$ 515.00$ & $\$ 2,158.00$ & $\$ 1,984.00$ & 8 & 65 \\
\hline Canon G1 & $9.9 \%$ & $\$ 190.00$ & $\$ 796.73$ & $\$ 709.99$ & 32 & 28 \\
\hline Compaq iPaq H3630 Pocket PC & $9.6 \%$ & $\$ 146.00$ & $\$ 578.20$ & $\$ 499.00$ & 5 & 70 \\
\hline Olympus C_2100 Ultra Zoom & $9.6 \%$ & $\$ 281.00$ & $\$ 748.45$ & $\$ 618.00$ & 42 & 80 \\
\hline Sony Cyber Shot DSC_P1 & $9.4 \%$ & $\$ 171.99$ & $\$ 693.61$ & $\$ 628.00$ & 21 & 73 \\
\hline Olympus C_3000 Zoom & $9.4 \%$ & $\$ 256.99$ & $\$ 657.75$ & $\$ 534.00$ & 46 & 76 \\
\hline Palm Vx & $9.2 \%$ & $\$ 103.00$ & $\$ 340.05$ & $\$ 296.00$ & 45 & 2 \\
\hline AMD ATHLON_900 384K CACHE SOCKA PGA462 TBIRD 200MHZ FSB & $9.1 \%$ & $\$ 49.30$ & $\$ 158.97$ & $\$ 140.88$ & 23 & 27 \\
\hline Plextor PlexWriter 12/10/32A CD_RW & $9.1 \%$ & $\$ 64.07$ & $\$ 211.84$ & $\$ 185.88$ & 33 & 4 \\
\hline HP DeskJet 930C & $9.1 \%$ & $\$ 59.43$ & $\$ 148.78$ & $\$ 125.00$ & 30 & 75 \\
\hline Kodak DC4800 Zoom & $9.1 \%$ & $\$ 135.01$ & $\$ 528.66$ & $\$ 464.98$ & 48 & 5 \\
\hline HP DeskJet 970CXI & $9.0 \%$ & $\$ 115.00$ & $\$ 288.32$ & $\$ 234.00$ & 38 & 32 \\
\hline Nikon Coolpix 950 & $8.7 \%$ & $\$ 250.01$ & $\$ 684.41$ & $\$ 559.99$ & 48 & 42 \\
\hline Olympus E_10 & $8.6 \%$ & $\$ 460.99$ & $\$ 1,857.35$ & $\$ 1,539.00$ & 45 & 56 \\
\hline Nikon Coolpix 880 & $8.5 \%$ & $\$ 211.00$ & $\$ 597.12$ & $\$ 498.00$ & 56 & 30 \\
\hline Asus A7V (Socket A) & $8.5 \%$ & $\$ 24.12$ & $\$ 144.18$ & $\$ 133.88$ & 5 & 9 \\
\hline Plextor PlexWriter 16X/10X40X & $8.5 \%$ & $\$ 71.07$ & $\$ 244.05$ & $\$ 208.88$ & 30 & 20 \\
\hline Sony Clie PEG_S300 & $8.5 \%$ & $\$ 112.05$ & $\$ 335.49$ & $\$ 286.95$ & 24 & 55 \\
\hline UPG_V Windows Millennium Edition from 95/98/98SE WME & $8.5 \%$ & $\$ 26.98$ & $\$ 90.88$ & $\$ 75.00$ & 27 & 35 \\
\hline Sony Cyber Shot DSC_S70 & $8.0 \%$ & $\$ 221.02$ & $\$ 714.68$ & $\$ 609.99$ & 46 & 12 \\
\hline Canon PowerShot S100 & $7.8 \%$ & $\$ 111.55$ & $\$ 445.44$ & $\$ 392.00$ & 53 & 8 \\
\hline
\end{tabular}


Table 1 (Continued): Price Dispersion on the Internet

\begin{tabular}{|c|c|c|c|c|c|c|}
\hline Product & $\left|\begin{array}{c}\text { Coefficient } \\
\text { of } \\
\text { Variation }\end{array}\right|$ & $\begin{array}{l}\text { Price } \\
\text { Range }\end{array}$ & $\begin{array}{c}\text { Average } \\
\text { Price }\end{array}$ & $\begin{array}{l}\text { Lowest } \\
\text { Price }\end{array}$ & $\begin{array}{c}\text { Number of } \\
\text { Sellers }\end{array}$ & $\begin{array}{l}\text { Product } \\
\text { Rank }\end{array}$ \\
\hline Norton AntiVirus 2001 7.0: Win9X/ME/NT 4 SP4/2K Pro/NT4 & $7.6 \%$ & $\$ 12.31$ & $\$ 38.66$ & $\$ 32.99$ & 24 & 83 \\
\hline Sony VAIO PCG_F650 (Pentium III 600 MHz, 64MB RAM, 12.0GB) & $7.6 \%$ & $\$ 371.00$ & $\$ 1,723.85$ & $\$ 1,628.00$ & 13 & 31 \\
\hline AMD ATHLON_1GHZ 384K CACHE SOCKA PGA 462 TBIRD $1 \mathrm{GHZ}$ & $7.4 \%$ & $\$ 57.59$ & $\$ 213.17$ & $\$ 189.88$ & 18 & 13 \\
\hline Sony VAIO PCG_F590 (Pentium III 750 MHz, 128MB RAM, 18GB) & $7.1 \%$ & $\$ 424.00$ & $\$ 2,219.56$ & $\$ 2,075.00$ & 9 & 16 \\
\hline Athlon Thunderbird_ $1200 \mathrm{MHz}(200 \mathrm{MHz} / 256 \mathrm{k})$ & $7.0 \%$ & $\$ 44.12$ & $\$ 225.27$ & $\$ 204.88$ & 11 & 39 \\
\hline Sony VAIO PCG_F630 (AMD K6_2 550MHz, 64MB RAM, 12.0GB) & $6.7 \%$ & $\$ 241.00$ & $\$ 1,258.86$ & $\$ 1,158.00$ & 14 & 38 \\
\hline Paint Shop Pro 7.0 : Win9X/2K/NT̄4 & $6.7 \%$ & $\$ 20.00$ & $\$ 91.80$ & $\$ 84.95$ & 16 & 26 \\
\hline ATXATHLON/DURON SA ATA 100 5USB A7V133/550/SWA & $6.6 \%$ & $\$ 29.12$ & $\$ 150.70$ & $\$ 136.88$ & 11 & 14 \\
\hline Palm Illc & $6.6 \%$ & $\$ 68.25$ & $\$ 311.50$ & $\$ 271.00$ & 44 & 29 \\
\hline ATi Radeon 64MB DDR & $6.3 \%$ & $\$ 51.07$ & $\$ 197.42$ & $\$ 183.88$ & 21 & 17 \\
\hline Nomad Jukebox Audio Player 6GB Silver & $6.2 \%$ & $\$ 101.99$ & $\$ 443.53$ & $\$ 398.00$ & 24 & 15 \\
\hline Nikon Coolpix 990 & $6.2 \%$ & $\$ 180.00$ & $\$ 795.25$ & $\$ 719.99$ & 48 & 3 \\
\hline PENTIUM III P3 1GHZ FCPGA 256KB L2 CACHE 133MHZ FSB 1GHZ EB & $6.1 \%$ & $\$ 62.47$ & $\$ 285.04$ & $\$ 263.88$ & 17 & 58 \\
\hline Athlon Thunderbird_ $1000 \mathrm{MHz}(200 \mathrm{MHz} / 256 \mathrm{~K})$ & $6.1 \%$ & $\$ 36.12$ & $\$ 174.65$ & $\$ 162.88$ & 12 & 87 \\
\hline WINDOWS 98 SECOND EDITION & $6.0 \%$ & $\$ 36.05$ & $\$ 176.66$ & $\$ 157.95$ & 19 & 66 \\
\hline ViewSonic PF790 & $6.0 \%$ & $\$ 104.07$ & $\$ 420.92$ & $\$ 365.88$ & 26 & 44 \\
\hline ATi All_in_Wonder Radeon 32MB & $5.8 \%$ & $\$ 52.06$ & $\$ 256.92$ & $\$ 237.89$ & 29 & 25 \\
\hline Windows Millennium Edition WME & $5.8 \%$ & $\$ 34.00$ & $\$ 176.31$ & $\$ 156.70$ & 28 & 84 \\
\hline Samsung Syncmaster 950P & $5.8 \%$ & $\$ 69.00$ & $\$ 295.53$ & $\$ 261.00$ & 19 & 60 \\
\hline Samsung SyncMaster 770 TFT & $5.7 \%$ & $\$ 210.99$ & $\$ 1,046.13$ & $\$ 929.99$ & 27 & 36 \\
\hline Palm M100 & $5.7 \%$ & $\$ 29.05$ & $\$ 144.15$ & $\$ 125.95$ & 37 & 68 \\
\hline Rio Volt Portable CD Player & $5.4 \%$ & $\$ 20.04$ & $\$ 163.06$ & $\$ 149.95$ & 12 & 41 \\
\hline Windows 2000 Professional W2K & $5.2 \%$ & $\$ 51.04$ & $\$ 273.27$ & $\$ 248.95$ & 30 & 63 \\
\hline Palm M105 & $5.1 \%$ & $\$ 29.11$ & $\$ 192.53$ & $\$ 173.95$ & 27 & 47 \\
\hline ViewSonic VG150 LCD ViewPanel & $5.0 \%$ & $\$ 141.11$ & $\$ 680.64$ & $\$ 618.88$ & 34 & 77 \\
\hline Creative Labs Sound Blaster Live Value & $5.0 \%$ & $\$ 5.17$ & $\$ 43.90$ & $\$ 41.99$ & 6 & 95 \\
\hline Linksys EtherFast 4_port Cable/DSL Router & $4.9 \%$ & $\$ 22.95$ & $\$ 135.60$ & $\$ 127.00$ & 29 & 18 \\
\hline Abit KT7_RAID (Socket A) & $4.8 \%$ & $\$ 10.00$ & $\$ 148.00$ & $\$ 143.00$ & 2 & 97 \\
\hline Handspring Visor Deluxe (Blue) & $4.7 \%$ & $\$ 39.01$ & $\$ 246.10$ & $\$ 225.99$ & 9 & 86 \\
\hline Adobe Acrobat 4.0: Win9X/NT4 SP3 & $4.7 \%$ & $\$ 35.11$ & $\$ 226.68$ & $\$ 206.89$ & 22 & 49 \\
\hline ATi Radeon 32MB DDR & $4.4 \%$ & $\$ 24.00$ & $\$ 153.49$ & $\$ 145.00$ & 25 & 51 \\
\hline Apple PowerBook G3/500_DVD (12GB HD) & $4.2 \%$ & $\$ 236.00$ & $\$ 2,436.20$ & $\$ 2,349.00$ & 5 & 96 \\
\hline HP LaserJet 2100xi & $4.2 \%$ & $\$ 98.05$ & $\$ 670.84$ & $\$ 614.95$ & 26 & 98 \\
\hline UPG Windows 2000 Professional W2K & $4.1 \%$ & $\$ 30.00$ & $\$ 190.44$ & $\$ 179.00$ & 25 & 61 \\
\hline Adobe Photoshop 6.0 UPG Win9X/ME/2K/NT4 & $4.1 \%$ & $\$ 24.01$ & $\$ 188.64$ & $\$ 177.99$ & 23 & 40 \\
\hline Handspring Visor Platinum & $4.0 \%$ & $\$ 26.01$ & $\$ 292.62$ & $\$ 272.99$ & 8 & 99 \\
\hline WIRELESS ACCESS POINT WLS NTWK & $3.8 \%$ & $\$ 43.60$ & $\$ 252.45$ & $\$ 235.00$ & 24 & 48 \\
\hline Linksys EtherFast 1_Port Cable/DSL Router & $3.8 \%$ & $\$ 13.00$ & $\$ 93.67$ & $\$ 86.95$ & 26 & 79 \\
\hline ETHERFAST WIRELESS AP PLUS CABLE/DSL ROUTER 4PORT SWITCH & $3.8 \%$ & $\$ 40.03$ & $\$ 257.86$ & $\$ 238.92$ & 15 & 81 \\
\hline Sonicblue Multimedia Rio PMP300 MP3 Player & $3.7 \%$ & $\$ 10.95$ & $\$ 153.47$ & $\$ 149.00$ & 3 & 22 \\
\hline Linksys EtherFast Cable/DSL Ethernet & $3.7 \%$ & $\$ 31.88$ & $\$ 192.88$ & $\$ 179.90$ & 25 & 100 \\
\hline HP LaserJet 1100xi & $3.6 \%$ & $\$ 65.04$ & $\$ 422.07$ & $\$ 388.95$ & 34 & 85 \\
\hline TDK veloCD ReWriter $12 X / 10 X / 32 X$ & $3.5 \%$ & $\$ 30.00$ & $\$ 231.06$ & $\$ 219.99$ & 20 & 78 \\
\hline Samsung SyncMaster 955DF & $3.4 \%$ & $\$ 40.54$ & $\$ 319.85$ & $\$ 308.21$ & 16 & 93 \\
\hline Lucent Orinoco RG_1000 Residential Wireless Networking Kit & $2.9 \%$ & $\$ 41.04$ & $\$ 396.79$ & $\$ 378.95$ & 9 & 92 \\
\hline Handspring Visor Edge (Silver) & $2.2 \%$ & $\$ 21.99$ & $\$ 396.00$ & $\$ 378.00$ & 6 & 94 \\
\hline Compaq Deskpro EXP3/800 10GB & $1.9 \%$ & $\$ 49.85$ & $\$ 1,029.36$ & $\$ 999.99$ & 5 & 50 \\
\hline Dell Dimension 4100 (933 MHz, 17 inch monitor, Office 2000 SBE) & $0.0 \%$ & $\$ 0.00$ & $\$ 1,588.00$ & $\$ 1,588.00$ & 1 & 37 \\
\hline 3dfx Voodoo5 5500 & $0.0 \%$ & $\$ 0.00$ & $\$ 179.00$ & $\$ 179.00$ & 1 & 46 \\
\hline Adobe Photoshop W/ImageReady 5.5: Win9X/NT4 & $0.0 \%$ & $\$ 0.00$ & $\$ 525.00$ & $\$ 525.00$ & 1 & 57 \\
\hline
\end{tabular}


Table 2: Parameter Estimates

\begin{tabular}{|c|c|c|c|c|}
\hline \multirow[t]{2}{*}{ Experiment } & \multirow[t]{2}{*}{ Treatment } & \multirow{2}{*}{$\begin{array}{c}\text { Experimental } \\
\text { Round }\end{array}$} & \multicolumn{2}{|c|}{ Parameter Estimates } \\
\hline & & & $\theta$ & $\lambda$ \\
\hline Dutch & Duopoly & All Rounds & 13.199 & 0.784 \\
\hline U.S. & Duopoly & All Rounds & 15.643 & 0.761 \\
\hline Dutch & Duopoly & Last Round & 20.214 & 0.457 \\
\hline U.S. & Duopoly & Last Round & 10.297 & 0.907 \\
\hline Dutch & Triopoly & All Rounds & 1.484 & 0.468 \\
\hline Dutch & Triopoly & Last Round & 0.870 & 0.488 \\
\hline Dutch & Quadopoly & All Rounds & 0.678 & 0.287 \\
\hline Dutch & Quadopoly & Last Round & 0.149 & 0.325 \\
\hline
\end{tabular}

Table 3: Implied Values of Epsilon

\begin{tabular}{|l|l|l|r|r|r|}
\hline \multirow{2}{*}{ Experiment } & Treatment & \multirow{2}{*}{$\begin{array}{c}\text { Experimental } \\
\text { Round }\end{array}$} & & \multicolumn{2}{|c|}{ Epsilon } \\
\cline { 4 - 6 } & & & $\begin{array}{c}\text { Experimental } \\
\text { Currency }\end{array}$ & $\begin{array}{c}\text { U.S. Dollar } \\
\text { Equivalent }\end{array}$ & $\begin{array}{c}\text { Epsilon as a } \\
\text { Percentage of } \\
\text { Monopoly } \\
\text { Profits }\end{array}$ \\
\hline Dutch & Duopoly & All Rounds & 0.871 & $\$ 0.026$ & $0.9 \%$ \\
\hline U.S. & Duopoly & All Rounds & 1.020 & $\$ 0.004$ & $0.8 \%$ \\
\hline Dutch & Duopoly & Last Round & 2.043 & $\$ 0.062$ & $2.0 \%$ \\
\hline U.S. & Duopoly & Last Round & 0.530 & $\$ 0.002$ & $0.4 \%$ \\
\hline Dutch & Triopoly & All Rounds & 0.126 & $\$ 0.004$ & $0.1 \%$ \\
\hline Dutch & Triopoly & Last Round & 0.054 & $\$ 0.002$ & $0.1 \%$ \\
\hline Dutch & Quadopoly & All Rounds & 0.096 & $\$ 0.003$ & $0.1 \%$ \\
\hline Dutch & Quadopoly & Last Round & 0.013 & $\$ 0.000$ & $0.0 \%$ \\
\hline
\end{tabular}


Table 4: Goodness of Fit Measures, All Rounds

\begin{tabular}{|c|c|c|c|c|c|c|c|c|c|c|c|c|c|}
\hline \multirow[t]{2}{*}{ Experiment } & \multirow[t]{2}{*}{ Treatment } & \multicolumn{4}{|c|}{ Sum of Squared Errors } & \multicolumn{4}{|c|}{ Correlation } & \multicolumn{4}{|c|}{ Sup Norm } \\
\hline & & Epsilon & QRE & Random & Nash & Epsilon & QRE & Random & Nash & Epsilon & QRE & Random & Nash \\
\hline Dutch & Duopoly & 0.192 & 0.706 & 2.831 & 22.140 & 0.992 & 0.983 & 0.930 & 0 & 0.108 & 0.138 & 0.280 & 0.958 \\
\hline US & Duopoly & 0.528 & 0.632 & 3.205 & 28.746 & 0.986 & 0.993 & 0.942 & 0 & 0.143 & 0.105 & 0.277 & 0.998 \\
\hline Dutch & Triopoly & 1.132 & 0.513 & 14.041 & 7.411 & 0.974 & 0.986 & 0.732 & 0 & 0.308 & 0.128 & 0.539 & 0.954 \\
\hline Dutch & Quadopoly & 0.892 & 1.414 & 9.639 & 8.958 & 0.975 & 0.978 & 0.805 & 0 & 0.276 & 0.213 & 0.505 & 0.896 \\
\hline
\end{tabular}


Table 5: Tests of Equality of Means, Observed Prices versus Those Predicted under Epsilon, QRE, Random, and Nash Behavior

\begin{tabular}{|c|c|c|c|c|c|c|c|}
\hline \multirow[t]{2}{*}{ Experiment } & \multirow[t]{2}{*}{ Treatment } & \multirow{2}{*}{$\begin{array}{c}\text { Experimental } \\
\text { Round }\end{array}$} & \multirow{2}{*}{$\begin{array}{c}\text { Observed } \\
\text { Mean } \\
\text { Price }\end{array}$} & \multicolumn{4}{|c|}{ Mean Price Under Null Hypothesis of } \\
\hline & & & & Epsilon & QRE & Random & Nash \\
\hline Dutch & Duopoly & All Rounds & 38.325 & $\begin{array}{r}40.362 \\
(.237)\end{array}$ & $\begin{array}{r}35.651 \\
(.121)\end{array}$ & $\begin{array}{r}51.000 \\
(.000)\end{array}$ & $\begin{array}{l}2.000 \\
(.000)\end{array}$ \\
\hline US & Duopoly & All Rounds & 48.513 & $\begin{array}{r}47.947 \\
(.628)\end{array}$ & $\begin{array}{r}42.807 \\
(.000)\end{array}$ & $\begin{array}{l}60.000 \\
(.000)\end{array}$ & $\begin{array}{l}0.000 \\
(.000)\end{array}$ \\
\hline Dutch & Duopoly & Last Round & 49.458 & $\begin{array}{r}52.931 \\
(.401)\end{array}$ & $\begin{array}{r}46.952 \\
(.634)\end{array}$ & $\begin{array}{r}51.000 \\
(.769)\end{array}$ & $\begin{array}{l}2.000 \\
(.000)\end{array}$ \\
\hline US & Duopoly & Last Round & 39.833 & $\begin{array}{r}36.039 \\
(.586)\end{array}$ & $\begin{array}{r}29.275 \\
(.134)\end{array}$ & $\begin{array}{r}60.000 \\
(.006)\end{array}$ & $\begin{array}{l}0.000 \\
(.000)\end{array}$ \\
\hline Dutch & Triopoly & All Rounds & 18.492 & $\begin{array}{r}23.303 \\
(.000)\end{array}$ & $\begin{array}{r}14.833 \\
(.007)\end{array}$ & $\begin{array}{r}51.000 \\
(.000)\end{array}$ & $\begin{array}{l}2.000 \\
(.000)\end{array}$ \\
\hline Dutch & Triopoly & Last Round & 15.125 & $\begin{array}{r}18.315 \\
(.480)\end{array}$ & $\begin{array}{l}8.771 \\
(.167)\end{array}$ & $\begin{array}{r}51.000 \\
(.000)\end{array}$ & $\begin{array}{l}2.000 \\
(.007)\end{array}$ \\
\hline Dutch & Quadopoly & All Rounds & 25.746 & $\begin{array}{r}28.559 \\
(.163)\end{array}$ & $\begin{array}{r}19.507 \\
(.002)\end{array}$ & $\begin{array}{r}51.000 \\
(.000)\end{array}$ & $\begin{array}{l}2.000 \\
(.000)\end{array}$ \\
\hline Dutch & Quadopoly & Last Round & 17.167 & $\begin{array}{r}18.036 \\
(.896)\end{array}$ & $\begin{array}{c}6.932 \\
(.134)\end{array}$ & $\begin{array}{r}51.000 \\
(.000)\end{array}$ & $\begin{array}{l}2.000 \\
(.031)\end{array}$ \\
\hline
\end{tabular}

Numbers in parenthesis are the P-values associated with the test that the observed mean price equals the mean price under the given null hypothesis. Italicized numbers indicate a failure to reject the null hypothesis at the 5 percent level. 
Table 6: Tests of Equality of Medians, Observed Prices versus Those Predicted under Epsilon, QRE, Random, and Nash Behavior

\begin{tabular}{|c|c|c|c|c|c|c|c|}
\hline \multirow[t]{2}{*}{ Experiment } & \multirow[t]{2}{*}{ Treatment } & \multirow{2}{*}{$\begin{array}{c}\text { Experimental } \\
\text { Round }\end{array}$} & \multirow{2}{*}{$\begin{array}{c}\text { Observed } \\
\text { Median } \\
\text { Price }\end{array}$} & \multicolumn{4}{|c|}{ Median Price Under Null Hypothesis of } \\
\hline & & & & Epsilon & QRE & Random & Nash \\
\hline Dutch & Duopoly & All Rounds & 29.500 & $\begin{array}{r}26.000 \\
(.090)\end{array}$ & $\begin{array}{r}33.000 \\
(.153)\end{array}$ & $\begin{array}{r}50.000 \\
(.000)\end{array}$ & $\begin{array}{l}2.000 \\
(.000)\end{array}$ \\
\hline US & Duopoly & All Rounds & 37.000 & $\begin{array}{r}31.000 \\
(.000)\end{array}$ & $\begin{array}{r}40.000 \\
(.001)\end{array}$ & $\begin{array}{r}59.000 \\
(.000)\end{array}$ & $\begin{array}{r}0.000 \\
(.000)\end{array}$ \\
\hline Dutch & Duopoly & Last Round & 41.000 & $\begin{array}{r}40.000 \\
(.832)\end{array}$ & $\begin{array}{r}45.000 \\
(.839)\end{array}$ & $\begin{array}{r}50.000 \\
(.286)\end{array}$ & $\begin{array}{l}2.000 \\
(.000)\end{array}$ \\
\hline US & Duopoly & Last Round & 25.000 & $\begin{array}{r}20.000 \\
(.233)\end{array}$ & $\begin{array}{r}27.000 \\
(.461)\end{array}$ & $\begin{array}{r}59.000 \\
(.000)\end{array}$ & $\begin{array}{r}0.000 \\
(.000)\end{array}$ \\
\hline Dutch & Triopoly & All Rounds & 11.000 & $\begin{array}{l}5.000 \\
(.000)\end{array}$ & $\begin{array}{r}12.000 \\
(.290)\end{array}$ & $\begin{array}{r}50.000 \\
(.000)\end{array}$ & $\begin{array}{l}2.000 \\
(.000)\end{array}$ \\
\hline Dutch & Triopoly & Last Round & 5.000 & $\begin{array}{l}3.000 \\
(.000)\end{array}$ & $\begin{array}{l}7.000 \\
(.093)\end{array}$ & $\begin{array}{r}50.000 \\
(.000)\end{array}$ & $\begin{array}{l}2.000 \\
(.000)\end{array}$ \\
\hline Dutch & Quadopoly & All Rounds & 10.500 & $\begin{array}{l}5.000 \\
(.000)\end{array}$ & $\begin{array}{r}16.000 \\
(.001)\end{array}$ & $\begin{array}{r}50.000 \\
(.000)\end{array}$ & $\begin{array}{l}2.000 \\
(.000)\end{array}$ \\
\hline Dutch & Quadopoly & Last Round & 5.000 & $\begin{array}{l}2.000 \\
(.000)\end{array}$ & $\begin{array}{r}5.000 \\
(1.00)\end{array}$ & $\begin{array}{r}50.000 \\
(.000)\end{array}$ & $\begin{array}{l}2.000 \\
(.000)\end{array}$ \\
\hline
\end{tabular}

Numbers in parenthesis are the P-values associated with the test that the observed median price equals the median price under the given null hypothesis. Italicized numbers indicate a failure to reject the null hypothesis at the 5 percent level. 
Table 7: Chi-Squared Tests of Equality of Observed Distribution of Prices with that under Epsilon, QRE, and Random Behavior

\begin{tabular}{|c|c|c|c|c|c|}
\hline \multirow[t]{2}{*}{ Experiment } & \multirow[t]{2}{*}{ Treatment } & \multirow{2}{*}{$\begin{array}{c}\text { Experimental } \\
\text { Round }\end{array}$} & \multicolumn{3}{|c|}{ Null Hypothesis: } \\
\hline & & & Epsilon & QRE & Random \\
\hline Dutch & Duopoly & All Rounds & 2.152 & 13.863 & 64.922 \\
\hline U.S. & Duopoly & All Rounds & 47.602 & 53.586 & 340.241 \\
\hline Dutch & Duopoly & Last Round & 4.284 & 2.535 & 6.930 \\
\hline U.S. & Duopoly & Last Round & 0.209 & 1.816 & 36.346 \\
\hline Dutch & Triopoly & All Rounds & 61.743 & 8.282 & 269.631 \\
\hline Dutch & Triopoly & Last Round & 11.106 & 7.099 & 25.783 \\
\hline Dutch & Quadopoly & All Rounds & 51.368 & 31.409 & 211.092 \\
\hline Dutch & Quadopoly & Last Round & 9.414 & 2.848 & 30.664 \\
\hline
\end{tabular}

Italicized numbers denote failure to reject the null hypothesis at the 5 percent level. 
Table 8: Tests of Equality of Standard Deviations, Observed Prices versus Those Predicted under Epsilon, QRE, Random, and Nash Behavior

\begin{tabular}{|c|c|c|c|c|c|c|c|}
\hline \multirow[t]{2}{*}{ Experiment } & \multirow[t]{2}{*}{ Treatment } & \multirow[t]{2}{*}{$\begin{array}{c}\text { Experimental } \\
\text { Round }\end{array}$} & \multirow{2}{*}{$\begin{array}{l}\text { Observed } \\
\text { Standard } \\
\text { Deviation }\end{array}$} & \multicolumn{4}{|c|}{$\begin{array}{c}\text { Standard Deviation Under Null Hypothesis } \\
\text { of }\end{array}$} \\
\hline & & & & Epsilon & QRE & Random & Nash \\
\hline Dutch & Duopoly & All Rounds & 26.649 & $\begin{array}{r}29.386 \\
(.041)\end{array}$ & $\begin{array}{r}17.555 \\
(.000)\end{array}$ & $\begin{array}{r}28.577 \\
(.144)\end{array}$ & $\begin{array}{l}0.000 \\
(.000)\end{array}$ \\
\hline US & Duopoly & All Rounds & 48.513 & $\begin{array}{r}35.252 \\
(.000)\end{array}$ & $\begin{array}{r}22.250 \\
(.000)\end{array}$ & $\begin{array}{r}34.929 \\
(.000)\end{array}$ & $\begin{array}{l}0.000 \\
(.000)\end{array}$ \\
\hline Dutch & Duopoly & Last Round & 25.434 & $\begin{array}{r}29.412 \\
(.401)\end{array}$ & $\begin{array}{r}23.723 \\
(.561)\end{array}$ & $\begin{array}{r}28.577 \\
(.509)\end{array}$ & $\begin{array}{l}0.000 \\
(.000)\end{array}$ \\
\hline US & Duopoly & Last Round & 47.993 & $\begin{array}{r}33.047 \\
(.000)\end{array}$ & $\begin{array}{r}15.411 \\
(.000)\end{array}$ & $\begin{array}{r}34.929 \\
(.000)\end{array}$ & $\begin{array}{l}0.000 \\
(.000)\end{array}$ \\
\hline Dutch & Triopoly & All Rounds & 20.744 & $\begin{array}{r}33.033 \\
(.000)\end{array}$ & $\begin{array}{l}8.841 \\
(.000)\end{array}$ & $\begin{array}{r}28.577 \\
(.000)\end{array}$ & $\begin{array}{l}0.000 \\
(.000)\end{array}$ \\
\hline Dutch & Triopoly & Last Round & 21.786 & $\begin{array}{r}30.283 \\
(.056)\end{array}$ & $\begin{array}{l}4.896 \\
(.000)\end{array}$ & $\begin{array}{r}28.577 \\
(.113)\end{array}$ & $\begin{array}{l}0.000 \\
(.000)\end{array}$ \\
\hline Dutch & Quadopoly & All Rounds & 31.108 & $\begin{array}{r}38.275 \\
(.000)\end{array}$ & $\begin{array}{r}12.766 \\
(.000)\end{array}$ & $\begin{array}{r}28.577 \\
(.000)\end{array}$ & $\begin{array}{l}0.000 \\
(.000)\end{array}$ \\
\hline Dutch & Quadopoly & Last Round & 32.232 & $\begin{array}{r}32.454 \\
(1.0)\end{array}$ & $\begin{array}{l}4.064 \\
(.000)\end{array}$ & $\begin{array}{r}28.577 \\
(.344)\end{array}$ & $\begin{array}{l}0.000 \\
(.000)\end{array}$ \\
\hline
\end{tabular}

Numbers in parenthesis are the P-values associated with the test that the sample standard deviation equals the standard deviation under the null hypothesis. Italicized numbers indicate a failure to reject the null hypothesis at the 5 percent level. 